A New Near-Zone Electric Field-Strength Meter

FRANK M. GREENE

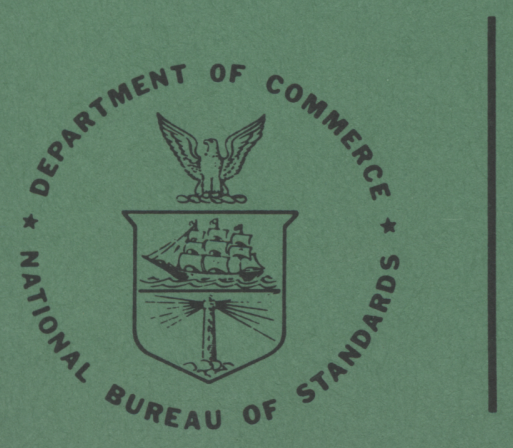

U.S. DEPARTMENT OF COMMERCE National Bureau of Standards 


\section{THE NATIONAL BUREAU OF STANDARDS}

The National Bureau of Standards ${ }^{1}$ provides measurement and technical information services essential to the efficiency and effectiveness of the work of the Nation's scientists and engineers. The Bureau serves also as a focal point in the Federal Government for assuring maximum application of the physical and engineering sciences to the advancement of technology in industry and commerce. To accomplish this mission, the Bureau is organized into three institutes covering broad program areas of research and services:

THE INSTITUTE FOR BASIC STANDARDS ... provides the central basis within the United States for a complete and consistent system of physical measurements, coordinates that system with the measurement systems of other nations, and furnishes essential services leading to accurate and uniform physical measurements throughout the Nation's scientific community, industry, and commerce. This Institute comprises a series of divisions, each serving a classical subject matter area:

-Applied Mathematics-Electricity-Metrology-Mechanics-Heat-Atomic Physics-Physical Chemistry-Radiation Physics-Laboratory Astrophysics ${ }^{2}$ - Radio Standards Laboratory, ${ }^{2}$ which includes Radio Standards Physics and Radio Standards Engineering-Office of Standard Reference Data.

THE INSTITUTE FOR MATERIALS RESEARCH ... conducts materials research and provides associated materials services including mainly reference materials and data on the properties of materials. Beyond its direct interest to the Nation's scientists and engineers, this Institute yields services which are essential to the advancement of technology in industry and commerce. This Institute is organized primarily by technical fields:

-Analytical Chemistry-Metallurgy-Reactor Radiations-Polymers-Inorganic Materials-Cryogenics ${ }^{2}$-Materials Evaluation Laboratory-Office of Standard Reference Materials.

THE INSTITUTE FOR APPLIED TECHNOLOGY ... provides technical services to promote the use of available technology and to facilitate technological innovation in industry and government. The principal elements of this Institute are:

-Building Research-Electronic Instrumentation-Textile and Apparel Technology CenterTechnical Analysis - Center for Computer Sciences and Technology-Office of Weights and Measures-Office of Engineering Standards Services-Office of Invention and Innovation-Clearinghouse for Federal Scientific and Technical Information. ${ }^{3}$

\footnotetext{
${ }^{1}$ Headquarters and Laboratories at Gaithersburg, Maryland, unless otherwise noted; mailing address Washington, D. C., 20234.

2 Located at Boulder, Colorado, 80302.

${ }^{3}$ Located at 5285 Port Royal Road, Springfield, Virginia, 22151.
} 
FRANK M. GREENE

Radio Standards Laboratory

National Bureau of Standards

Boulder, Colorado

NBS Technical Notes are designed to supplement the Bureau's regular publications program. They provide a means for making available scientific data that are of transient or limited interest. Technical Notes may be listed or referred to in the open literature.

For sale by the Superintendent of Documents, U.S. Government Printing Office, Washington, D.C., 20402 Price: 35 cents. 

ABSTRACT .

1. INTRODUCTION

2. THE "SEMI-CONDUCTING" PLASTIC TRANSMISSION LINE • 2

2. 1 Errors Caused by Metallic Lines . . . . . . . . . 2

2. 2 The Use of a Non-Metallic Line . . . . . . . . . 3

2. 3 Description of the "Semi-Conducting" Line. . . . . . 3

2. 4 Electrical Characteristics of the Line . . . . . . . 4

3. DESCRIPTION OF THE NBS FIELD-STRENGTH METERS • . 5

3.1 Principles of Operation . • • • • • • • • . . 5

3.2 Electrical Design . . . . . . . . . . . . . 9

3.2. 1 General • • • • • . . . . . . • . . . 9

3.2.2 The Dipole Antenna . . . . . . . . . . 10

3.2.3 RF Capacitive Step Attenuator . . . . . . . 17

3.2. 4 Band-Pass Amplifier and Detector . . . . . . 19

3.2.5 Calibrating Oscillator and Detector. . . . . 25

3.2.6 Remote Indicator Unit . . . . . . . . . . 31

3. 2.7 The Assembled Field-Strength Meter . . . . 35

4. DASA FINAL ACCEPTANCE TESTS • . . . . . . . 39

4. 1 General . . . • . . . . . . . • . . . . 39

4. 2 Low-Frequency Tests. . . . . . . . . . . 39

4.3 High-Frequency Tests. . . . . . . . . . . . 43

4. 4 Summary of Tests . . . . . . . . . . . . . . 45

5. ACKNOWLEDGEMENT • • • • • • • • • • • • . . 46

6. BIBLIOGRAPHY • . . . . . . . . . . . . . . 47 

Fig. 1 Block Diagram of the NBS Field-Strength Meter . . . 6

Fig. 2 Cutaway Drawing of the Measuring Dipole . . . . . . 11

Fig. 3 View of the Complete Measuring Dipole . . . . . . . 13

Fig. 4 Detector-DC-Output Transfer-Wiring Schematic . . . 14

Fig. 5 Circuitry of Capacitive Step Attenuator . . . . . . . 16

Fig. 6 Basic Layout of RF Band-Pass Amplifier . . . . . . 18

Fig. 7 Circuit of Band-Pass RF Amplifier (150 to $250 \mathrm{kHz}$ ). . 20

Fig. 8 Circuit of Band-Pass RF Amplifier (18 to $30 \mathrm{MHz}$ ) . . . 21

Fig. 9 Seven-Pole Butterworth Band-Pass Filter ( $f=200 \mathrm{kHz}$ ) 22

Fig. 10 Six-Pole Tschebyscheff Band-Pass Filter $\left(f_{0}^{\circ}=24 \mathrm{MHz}\right) \cdot 23$

Fig. 11 Nominal Overall Selectivity Characteristics of the Two Band-Pass Amplifiers. . . . . . . . . . . . 24

Fig. 12 Basic Layout of Calibrating Oscillator . . . . . . 26

Fig. 13 Circuit of Low $-F r$ equency Calibrating Oscillator $(150$ to $250 \mathrm{kHz})$. . . . . . . . . . . . . . . 28

Fig. 14 Circuit of High-Frequency Calibrating Oscillator $(18$ to $30 \mathrm{MHz})$. . . . . . . . . . . . . . 29

Fig. 15 Basic Layout of Remote Indicator Unit . . . . . . 30

Fig. 16 Circuit of DC Vacuum-Tube Voltmeter . . . . . . 32

Fig. 17 Circuit of Audio-Amplifier Beat-Indicator . . . . . . 33

Fig. 18 View of the Measuring Dipole and Mounting Gimbal . . 34

Fig. 19 The Complete Near-Zone Field-Strength Meter . . . 36

Fig. 20 View of the Remote Indicator Unit. . . . . . . . 37

Fig. 21 Low-Frequency DASA Acceptance Tests. . . . . . . 40

Fig. 22 Vertical Electric Field of a 35-Foot Monopole. . . . . 42

Fig. 23 Vertical Electric Field of a $\lambda / 4$ Monopole . . . . . . 44

TABLES

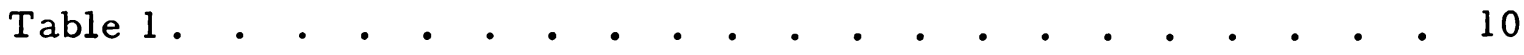





\title{
A NEW NEAR-ZONE ELECTRIC FIELD-STRENGTH METER
}

\author{
Frank M. Greene
}

Abstract-The National Bureau of Standards has recently completed the development of prototype instrumentation for measuring the electricfield components of complex, high-level, near-zone electromagnetic fields from 0.1 to 1000 volts per meter, at frequencies from $150 \mathrm{kHz}$ to $30 \mathrm{MHz}$ with a present uncertainty of less than $\pm 2 \mathrm{~dB}$. The design of the NBS meters is based on the use of a novel form of telemetry, employing a completely non-metallic electrical transmission line, which apparently has not been fully exploited heretofore. This avoids the perturbing effects on the field being measured, usually caused by fieldstrength meters employing metallic RF transmission lines. The design and performance of the meter are discussed in some detail.

\section{Introduction}

The National Bureau of Standards, under the sponsorship of the Defense Atomic Support Agency, has recently completed the development of prototype instrumentation for measuring the electric-field components of complex, high-level, near-zone electromagnetic fields. The instrumentation is capable of measuring both the magnitude and direction of elliptically polarized $\mathrm{CW}$ electric fields having strengths in the range from 0.1 to 1000 volts per meter at frequencies from $150 \mathrm{kHz}$ to $30 \mathrm{MHz}$. This represents one step in the effort to develop accurate and meaningful measuring and calibrating instrumentation, for use in evaluating hazards of electromagnetic radiation to electro-explosive ordnance devices. It is well known that high-level fields of powerful nearby radio transmitters may cause premature detonation of missile and rocket type weapons during storage or loading operations on shipboard, or at other military installations. It was from the standpoint of improving both the weapons reliability, as well as the safety of operating personnel and equipment, that the program was undertaken. 
The design of the NBS meters is based on the use of a novel form of telemetry, employing a completely non-metallic electrical transmission line to avoid perturbing the field being measured. This approach has apparently not been fully exploited, heretofore. The extremely-high RF loss of the line used attenuates any RF currents induced on the line by the surrounding field and essentially eliminates re-radiation from the line, or unwanted coupling between the line and the measuring antenna. The high line-loss, however, necessitates miniaturizing the RF portions of the receiving and calibrating instrumentation and placing them and the associated battery supplies inside the measuring antenna. The field information contained in the detected DC-AF output of the receiver is transmitted over the line to a remote readout unit, where the strength of the electric-field component parallel to the axis of the antenna is read directly.

Interim electric-field standards and calibration techniques were also developed at NBS to evaluate the performance of the field-strength meters during their development, as well as to provide a tentative calibration of the completed instruments. The present uncertainty of the standards is believed to be less than $\pm 2 \mathrm{~dB}$, but further development effort is expected to reduce this to less than $\pm 1 \mathrm{~dB}$.

\section{The New "Semi-Conducting" Plastic Transmission Line}

\section{1 Errors Caused by Metallic Lines.}

In the past, electric field-strength meters have usually made use of a long metallic RF transmission line to connect the measuring antenna with its receiver, usually located at a point remote from the antenna. Such metallic lines often cause large measurement errors, especially when measuring near-zone fields having complex spatial distributions. In these cases, a neutral-field path, along which the line can be placed, 
either seldom exists, or the orientation of such a path, if it does exist is usually not known in advance of making the measurements. Under these conditions, it is difficult or impossible to orient the line so that it is everywhere normal to existing electric-field components. Thus, the line not only may perturb the field being measured, but unwanted RF currents induced on the line can be coupled into the antenna and contribute to the total response of the field-strength meter.

\section{2 The Use of a Non-Metallic Line.}

The NBS near-zone meters avoid this difficulty by making use of a special non-metallic balanced transmission line in which the conductor RF loss has been purposely made extremely high compared to that of the usual copper line. If the conductors are made of sufficiently high resistance material, the line can be made essentially "transparent" to the surrounding field. This is to say that the RF currents induced on the transmission line by the field will be negligibly small, resulting in insignificant reradiation, or that any RF energy propagating along the line will be heavily attenuated because of the extremely high loss of the line. It has been found that this can be achieved if the volume resistivity of the conductor material used is of the order of a million times or more higher than that of copper. This is roughly midway (on a logarithmic scale) between the volume resistivity of metals, on the one hand, and that of insulators such as glass or mica on the other. Such materials can therefore be said to be "semi-conducting."

\section{3 Description of the "Semi-Conducting" Line.}

The material used in the NBS lines is basically polytetrafluoroethylene (PTFE), rendered "semi-conducting" by uniformly dispersing finely-divided carbon black (approximately 30 percent by weight) throughout the plastic while it is in the semi-fluid state during its manufacture. 
Tests at NBS have indicated the PTFE material to be more stable electrically than other types tried, such as silicone rubber, polyethylene, carbon-coated multi-fiber glass, etc. Other types of conductor materials (including high-resistance metallic alloy wire and thin deposited metallic films) were examined, but were not found to be practical for this use, either because of unsuitable electrical characteristics or excessive cost.

Several parallel-conductor balanced transmission lines were made at NBS using the semi-conducting PTFE material. The line conductors are in the form of 0.03 inch diameter monofilaments in place of the usual copper conductors. They are coated with a thin nylon film (approximately 0.005 inch thick) to further improve their strength and electrical stability. Each of the filaments is in turn enclosed in a vinyl-coated woven fiber-glass sleeve approximately 0.1 inch O. D. Two such insulated conductors are encased in a polyvinyl chloride outer jacket, for added strength and protection, to form the completed transmission line. Military Type JJ-048 or PJ-291 twin-conductor plugs are used at the two ends for connecting to the dipole antenna, and to the remote indicator unit, respectively. The overall length of the lines is approximately 30 feet.

\section{4 Electrical Characteristics of the Line.}

The "semi-conducting" PTFE material used in the line has a volume resistivity of approximately $3.0 \mathrm{ohm}-\mathrm{cm}$ (compared to $1.7 \times 10^{-6}$ ohm-cm for copper), giving a resistance of approximately 20,000 ohms per lineal foot, or a loop resistance of approximately 1.2 megohms for a line 30 feet in length. The measured mutual capacitance between the two line conductors is approximately $10 \mathrm{pF}$ per foot, or roughly $300 \mathrm{pF}$ for the entire line. The transmission loss, to the desired field-strength information at DC and low AF, is negligible if a high-impedance DC-AF 
vacuum-tube voltmeter is used as the readout device at the receiving end of the line. The line attenuation increases as the square-root of frequency, reaching a theoretical as well as a measured value of approximately $53 \mathrm{~dB}$ per foot at a frequency of $30 \mathrm{MHz}$, for the differential mode of transmission. The common-mode attenuation with the line lying flat on a metal ground plane turns out to have essentially the same value. The use of a high-loss, parallel-conductor, balanced transmission line of this type has been found to reduce the perturbation of the surrounding field by more than two orders of magnitude below that existing in the case of a copper line. This renders any effect of the line on the field wholly negligible in most instances.

A type of "flexural" noise is generated on the "semi-conducting" transmission line when it is suddenly flexed or moved physically. The common-mode component of this "noise" may be relatively high, having a peak value of several volts on open circuit, for a 30 foot line. However, the differential-mode component is appreciably smaller, having a peak value of the order of 0.2 volt with the line open circuited at both ends. This can be decreased to approximately 0.02 volt by terminating either the sending or receiving end of the line in a resistance of 10 megohms. This noise does not present a problem in the NBS meters where the level of transmission over the balanced line is in the range 0.75 to 7.5 volts, as shown in Table 1 .

\section{Description of the NBS Field-Strength Meters}

\section{1 Principles of Operation.}

Two prototype, near-zone, CW electric field-strength meters were developed for the Defense Atomic Support Agency. These meters cover the frequency ranges 150 to $250 \mathrm{kHz}$, and 18 to $30 \mathrm{MHz}$, respectively, and are capable of measuring fields over the range 0.1 to 1000 volts per 


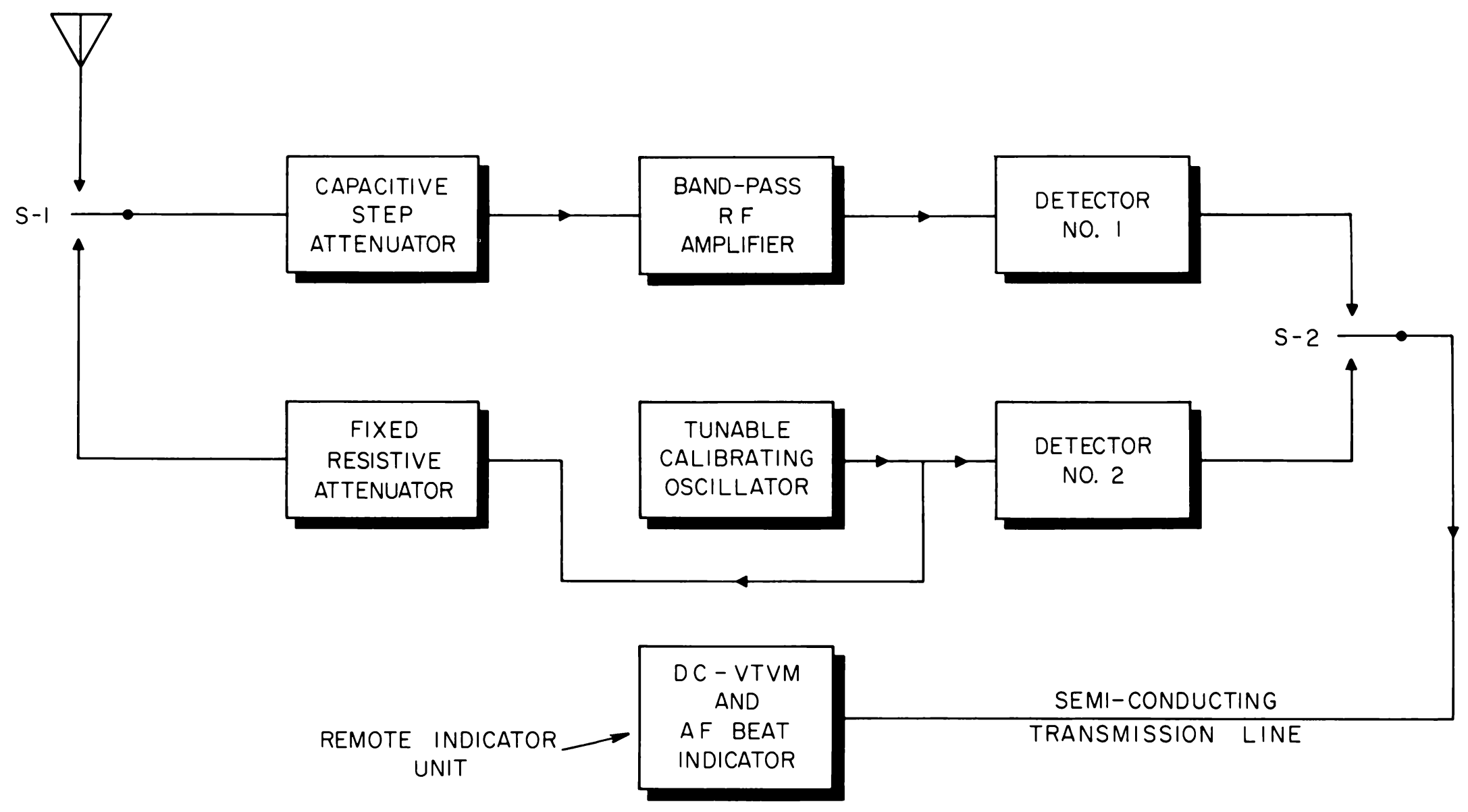

FIG. I BLOCK DIAGRAM OF THE NBS FIELD-STRENGTH METER 
meter (RMS). Both meters make use of a selective TRF receiver to amplify the voltage induced in the receiving antenna by the component of the electric field being measured. The detected output of the receiver is transmitted over the special non-metallic transmission line to a remote indicator unit where the strength of the field is read directly. A block diagram of the basic circuitry is shown in Fig. 1.

These meters employ the same basic method of receiver-gain calibration that has been used in CW-type field-strength meters in this country for many years. Meters of this basic type are somewhat simpler in construction, but, at the same time, have proven themselves to have much better long-term amplitude stability than present-day socalled "interference" meters.

A CW oscillator is included to permit calibrating the overall receiver gain periodically during a sequence of measurements in the field. This oscillator is tunable over the same frequency range as the receiver. This method permits setting the receiver gain each time to the same value that existed when the instrument was previously calibrated in a standard field.

The receiver portion of the field-strength meter consists basically of an RF input capacitive step attenuator, a fixed-tuned band-pass RF amplifier (with manual gain control), and a diode detector. The internal calibrating oscillator is tunable over the pass-band of the receiver to permit adjusting the receiver gain to a "standard" value for any signal frequency within its pass band. The RF output level of the oscillator is monitored by its own detector. During calibration this output is applied to the receiver input through a fixed resistive attenuator and transfer switch, S-1. With the receiver input attenuator set to its reference or "calibrate" position, the receiver gain is manually adjusted until the DC outputs of detectors 1 and 2 are identical. The exact output level of the 
calibrating oscillator is not important and need not be known, nor does it have to be exactly the same each time a calibration is performed. However, it is important that the oscillator detector remain stable. In this way, slow changes in the gain of the receiver (including its detector) due to variations in ambient temperature, battery supply voltage, component aging, tuning drift, etc., are compensated for each time the receiver gain is calibrated.

While not a necessary condition, it can be seen, for simplicity, that if detectors 1 and 2 have identical characteristics, the loop gain of the circuitry between them is adjusted to unity each time the fieldstrength meter is calibrated. That is, the overall amplifier gain is adjusted so that it is equal to the total loss in the two tandem attenuators. The overall long-term calibration stability of this field-strength meter is thus seen to depend principally upon the stability of the two attenuators and the oscillator detector. These components are relatively easy to stabilize. The RF amplifier need have only relatively good short-term stability over the period between interim calibrations in the field of roughly 30 minutes or so. The calibrating oscillator, on the other hand, only needs to have good short-term amplitude stability over a period of roughly 60 seconds or so, during calibration procedures in the field, or whenever the instrument is being calibrated in a standard field.

The original design goals, followed in developing these fieldstrength meters, specified the measurement of the field strength produced by a single CW source. If two signals, having different frequencies, were present within the fixed-tuned pass-band of the instrument, the resulting response would tend toward the peak of the combined, or composite input, rather than the RMS, or average. 


\section{2 Electrical Design.}

\subsection{General.}

The two near-zone TRF electric field-strength meters developed at NBS-BL consist of the following principal components:

(a) a short hollow cylindrical dipole antenna in which is induced an RF voltage proportional to the component of the electric field parallel to the dipole axis;

(b) an RF capacitive step attenuator, contained within the dipole, to reduce the antenna-output RF voltage to the working level of the receiver;

(c) a miniaturized solid-state selective amplifier (or receiver) and $\mathrm{CW}$ calibrating oscillator, both contained within the hollow dipole antenna, along with their respective battery supplies;

(d) a special semi-conducting plastic transmission line, approximately 30 feet in length, over which the detected DC-AF output of the receirer is transmitted;

(e) a remote-indicator unit where the strength of the desired component of the electric field is read directly on a highly-stable batteryoperated vacuum-tube voltmeter. A miniaturized solid-state audio amplifier and speaker are included for use as a zero-beat tuning indicator, when adjusting the frequency of the calibrating oscillator to that of the field being measured.

Before discussing these components in detail, it is of interest to examine the range of nominal RF voltage levels over which they will operate. The components are all directly interrelated in their electrical design. As an example, the required RF amplifier gain is dictated by several factors, some of which are: the dipole length as well as its internal and residual capacitances; the required linearity of response and dynamic range; the "flexural" noise level of the semi-conducting plastic transmission line. 
A list of the various ranges of $R F$ voltage over which the principal components operate is shown in Table 1 for the range of electric field strength from 0.1 to 1000 volts per meter. An explanation of how the ranges were calculated is given in the following:

Effective Length of Measuring Dipole......, L $\mathrm{L}_{\text {of }} \cong 0.15 \mathrm{~m}$

Induced Voltage in Dipole............... $V_{1}=E \cdot L_{\text {off }}$

Dipole Voltage-Transfer Ratio, $V_{0} / V_{1}=C_{a} /\left(C_{a}+C_{s}\right) \cong 0.20$

$\mathrm{C}_{\mathrm{a}} \equiv$ Internal Capacitance of Dipole ......, $\mathrm{C}_{\mathrm{a}} \cong 3 \mathrm{pF}$

$\mathrm{C}_{\mathbf{8}} \equiv$ Residual Gap and Circuit Capacitance.., $\mathrm{C}_{\mathbf{5}} \cong 12 \mathrm{pF}$

RF Amplifier Nominal Voltage Gain......, $V_{2} / V_{1} \cong 100$

\section{TABLE 1}

DISTRIBUTION OF NOMINAL OPERATING·RF-VOLTAGE LEVELS (in the TRF field-strength meter)

\begin{tabular}{|l|c|c|c|c|c|c|}
\hline$E(V / m)$ & $a(d B)$ & $V_{1}$ (volts) & $V_{0}$ (volts) & $V_{1}$ (volts) & $V_{2}$ (volts) & $V_{3}$ (volts) \\
\hline \hline $0.1-1.0$ & 0 & $.015-0.15$ & $.003-0.03$ & $0.003-0.03$ & $0.3-3.0$ & $0.75-7.5$ \\
$1.0-10$. & 20 & $0.15-1.50$ & $0.03-0.30$ & $0.003-0.03$ & $0.3-3.0$ & $0.75-7.5$ \\
$10 .-10^{2}$ & 40 & $1.50-15.0$ & $0.30-3.00$ & $0.003-0.03$ & $0.3-3.0$ & $0.75-7.5$ \\
$10^{2}-10^{3}$ & 60 & $15.0-150$. & $3.00-30.0$ & $0.003-0.03$ & $0.3-3.0$ & $0.75-7.5$ \\
\hline
\end{tabular}

$\mathrm{E}(\mathrm{V} / \mathrm{m}) \equiv$ Electric Field Strength, volts per meter

$a(d B) \equiv$ Measuring Dipole Attenuator Setting

$V_{1} \quad \equiv$ Induced Voltage in Measuring Dipole

$\mathrm{V}_{\circ} \quad \equiv$ Output Voltage of Measuring Dipole

$\mathrm{V}_{1} \quad \equiv$ Input Voltage to RF Amplifier

$\mathrm{V}_{2} \quad \equiv$ Output Voltage of RF Amplifier

$V_{3} \quad \equiv$ Output Voltage of Amplifier Detector (DC)

\section{2. 2 The Dipole Antenna.}

A cutaway drawing of the measuring dipole is shown in Fig. 2, and a view of the complete assembly is shown in the upper portion of Fig. 3. The two dipole cylinders are made of gold-plated copper tubing 1-3/8 inches outside diameter, with a $1 / 32$ inch insulating gap between them at the center. They are aligned and held together by an epoxy-glass sleeve as shown. The overall length of the antenna is approximately 


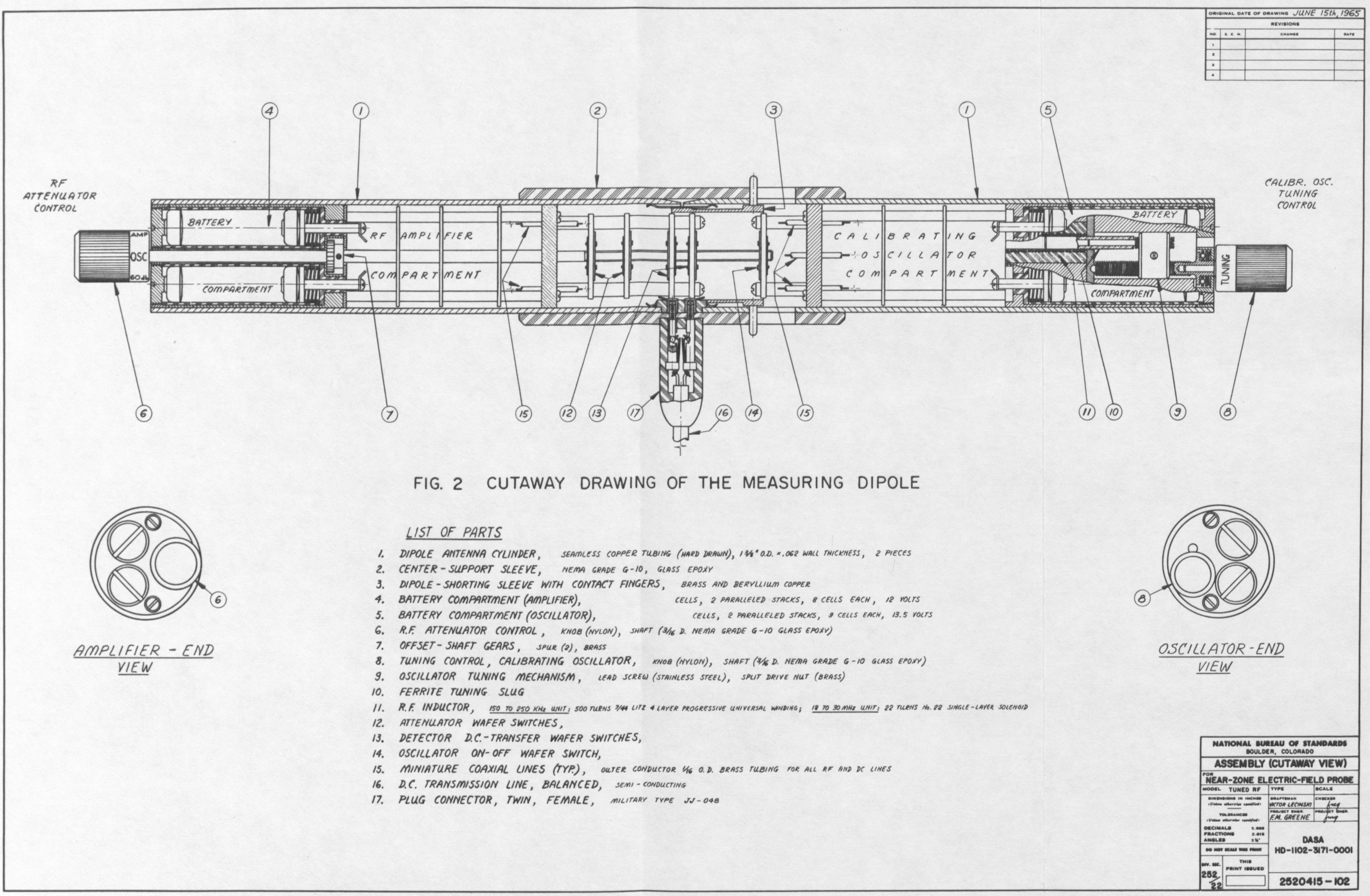





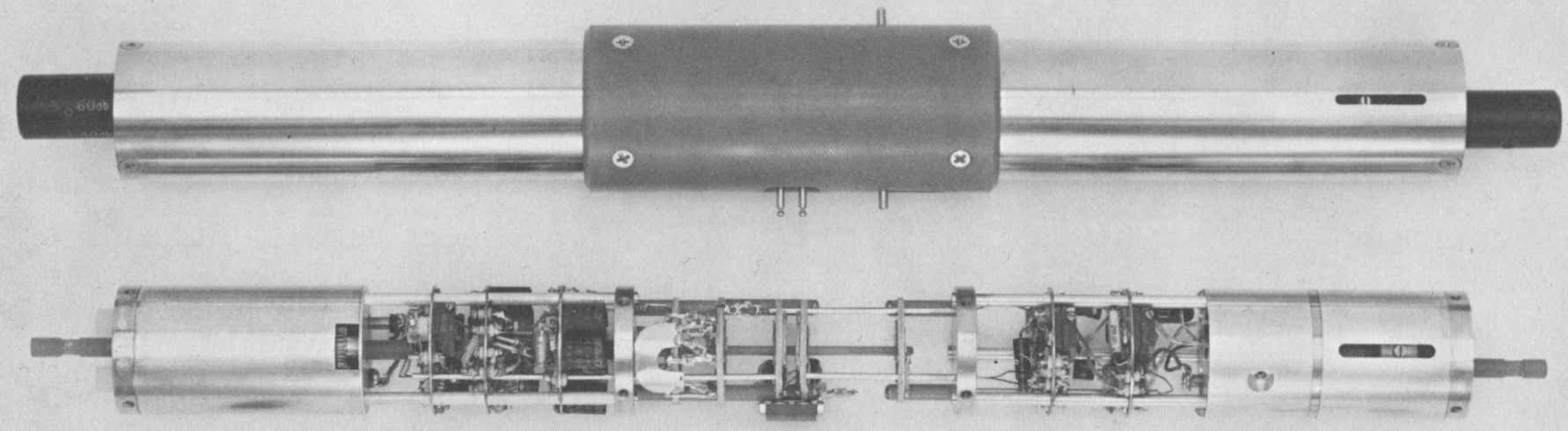

$\stackrel{\varpi}{\omega}$

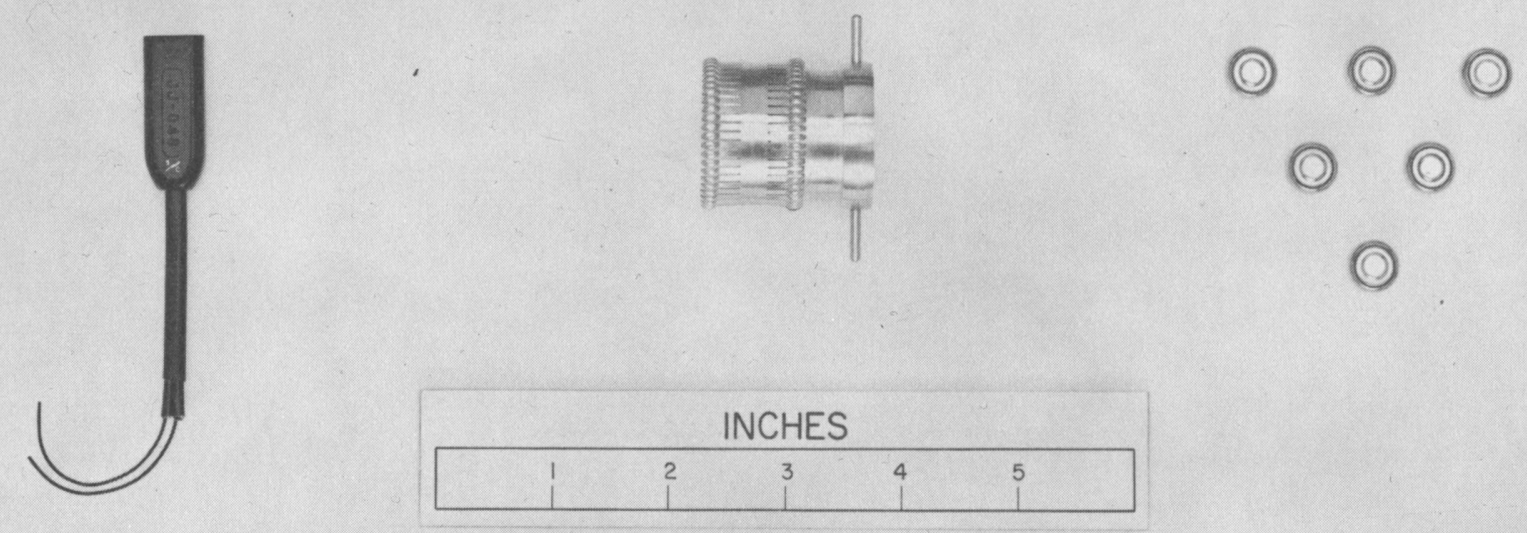

FIG. 3 VIEW OF THE COMPLETE MEASURING DIPOLE 


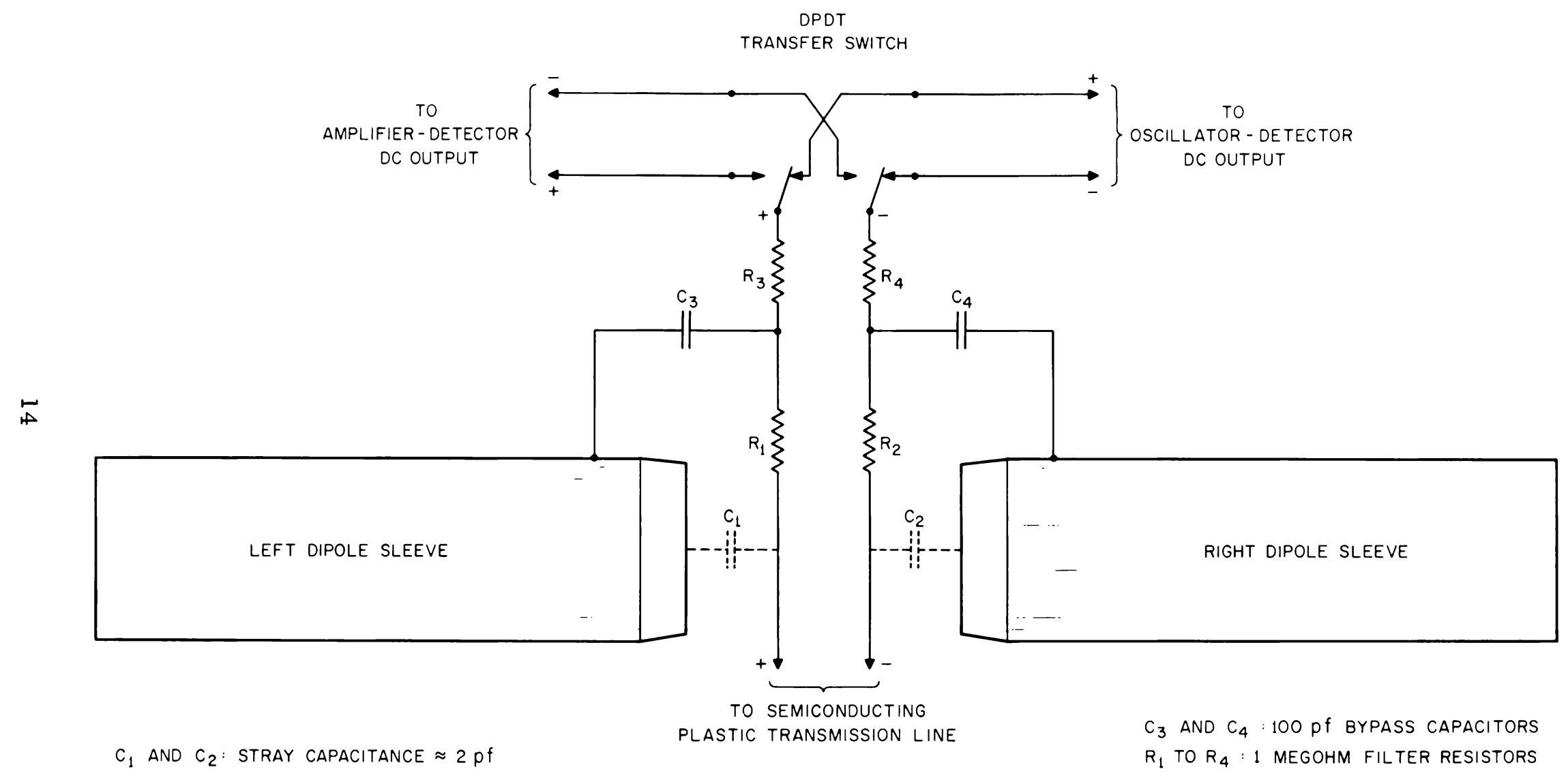

FIG. 4 DETECTOR-DC-OUTPUT TRANSFER-WIRING SCHEMATIC 
13 inches, not including the nylon control knob on each end. A view of the interior instrumentation with the copper dipole sleeves removed is shown in the central portion of Fig. 3. The miniaturized, solid-state, band-pass amplifier (receiver) and its battery supply are in the left half of the dipole. The tunable $\mathrm{CW}$ calibrating oscillator and its battery supply are in the right half. The RF capacitive step attenuator is located in the central portion of the dipole, and is comprised of the two rotary wafer switches on the extreme left and associated fixed capacitors. The two center wafers comprise a DPDT switch used for transferring the semi-conducting line to the DC output of either the amplifier detector or the oscillator detector. The single wafer switch on the extreme right of center energizes the calibrating oscillator when the attenuator control knob (located on the extreme left end of the dipole) is in either of the CALIBRATE positions. At the bottom of Fig. 3 are shown (left to right):

(a) a short piece of the semi-conducting plastic transmission line and its twin-conductor plug;

(b) an internal dipole-shorting sleeve, used to attenuate strong local signals while calibrating the amplifier gain;

(c) some of the miniature silver-oxide cells used in the internal battery supplies.

The transmission-line plug connects to the two stainless-steel pins at the center of the dipole. The detector DC-transfer and RF-filtering circuitry is shown in Fig. 4. The RF filter is composed of resistors Rl to $\mathrm{R} 4$ and bypass capacitors $\mathrm{C} 3$ and $\mathrm{C} 4$. It serves to preserve the electrical symmetry or balance of the dipole with respect to the transmission line, and to attenuate any transverse, as well as common-mode RF pickup that might exist on the line. Special care was exercised in the design and construction of the measuring dipole, so as to maintain accurate electrical symmetry. This is essential if the antenna is to respond only 

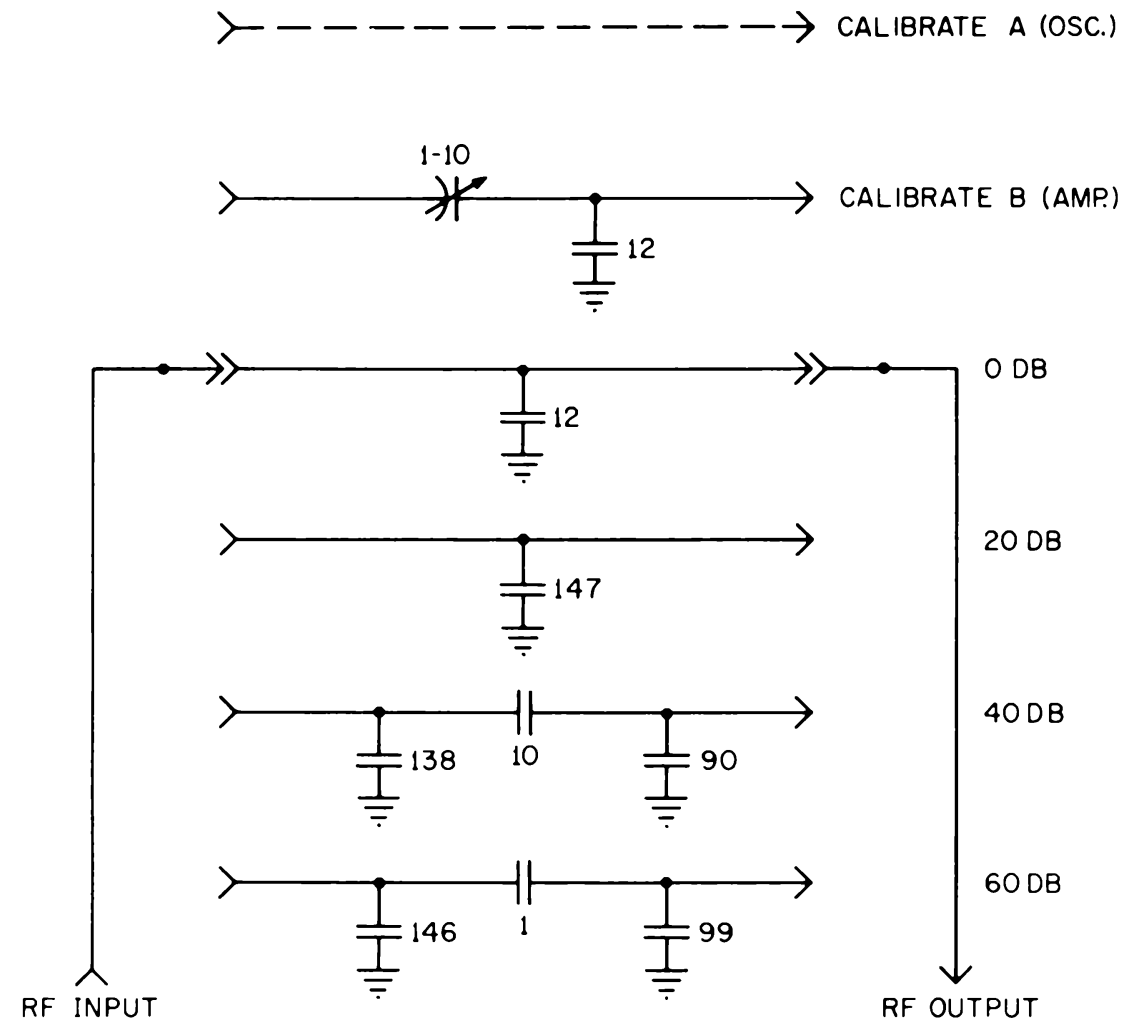

FIG. 5 CIRCUITRY OF CAPACITIVE STEP ATTENUATOR (CAPACITANCE VALUES SHOWN ARE NOMINAL VALUES IN pf, AND INCLUDE WIRING AND RESIDUAL CAPACITANCES.) 
to the component of the electric field parallel to its axis. The electrical symmetry, or balance, of the NBS dipole is such that its response to the cross-polarized component of the electric field is $40 \mathrm{~dB}$ or more below its principal response.

It can be shown that if the length of the measuring dipole does not exceed 0.03 wavelength, its effective length when measuring a field having a highly-complex spatial distribution will not differ by more than 2 or 3 percent (in the worst case) from the effective length when immersed in a uniform plane wave. Likewise, the interaction error, resulting from coupling between such a short antenna and its image, will be small provided the loading is light and that measurements are not made closer than two or three feet to the ground or large metallic objects.

\subsection{RF Capacitive Step Attenuator.}

The circuitry and capacitance values used in this attenuator are shown in Fig. 5. This unit is constructed using special 60-degree detent, subminiature, rotary wafer switches (glass-silicone wafers and coin-silver contacts). The fixed capacitors used are low-temperature coefficient ceramic miniatures. Special capacitance values, which have been selected to 1 percent tolerance, are used as shown. The input and output trimmer capacitors (not shown) are 1-10 pF ceramic subminiatures. The step attenuator proper has four positions, 0, 20, 40, and $60 \mathrm{~dB}$, with two additional $0 \mathrm{~dB}$ positions, Calibrate $\mathrm{A}(\mathrm{OSC})$ and Calibrate $B(A M P)$. In the latter two positions, the calibrating oscillator is turned $\mathrm{ON}$, and the semi-conducting plastic transmission line can then be switched between the DC outputs of the oscillator and amplifier detectors while calibrating the amplifier gain.

The attenuator design is based on a dipole internal capacitance of $3 \mathrm{pF}$ and a residual gap and circuit capacitance of $12 \mathrm{pF}$, as given in 


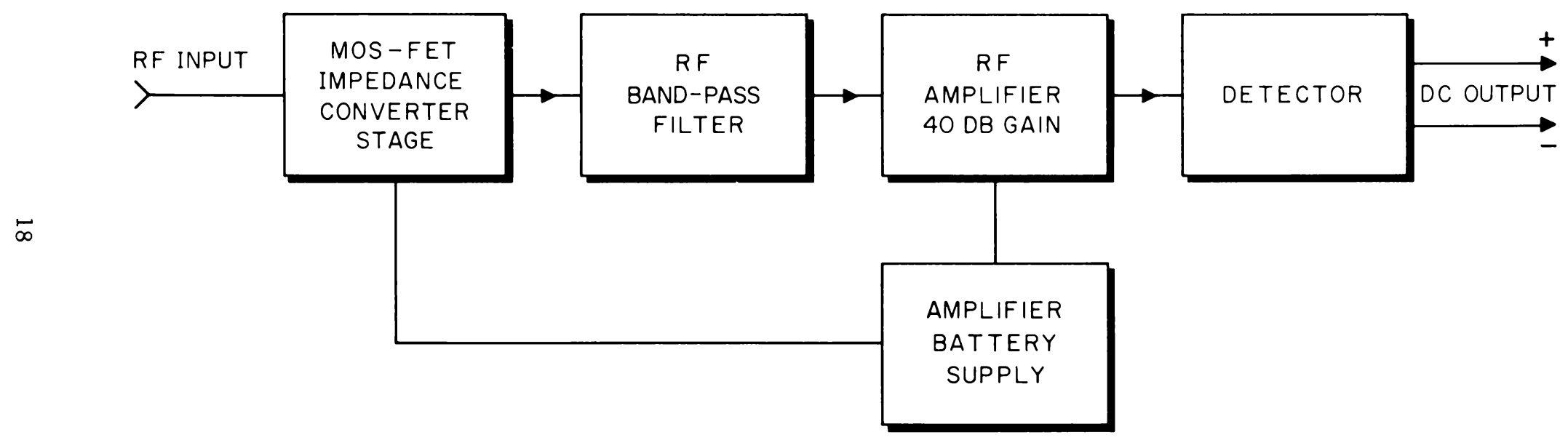

FIG. 6 BASIC LAYOUT OF RF BAND-PASS AMPLIFIER 
Table 1. The latter value is the total input-circuit capacitance when the attenuator is in the $0-d B$ position. In the 40 and $60 \mathrm{~dB}$ positions, the residual capacitance divides into two parts, $7 \mathrm{pF}$ for the antenna or input side of the attenuator, and $5 \mathrm{pF}$ for the amplifier or output side. The overall size of the complete miniaturized attenuator module is approximately 1 inch diameter by 1 inch long.

\section{2. 4 Band-Pass Amplifier and Detector.}

The basic layout of this unit is shown in the block diagram of Fig. 6. In order to provide a high input impedance, so as not to appreciably load the dipole antenna or the capacitive step attenuator, a Metal-OxideSilicon Field-Effect Transistor (MOS-FET) is used in the first stage as an untuned input-impedance converter (source-follower configuration). This is an insulated-gate $\mathrm{N}$-channel FET having an extremely high input resistance of several megohms and a low input capacitance of approximately $2 \mathrm{pF}$. In order to protect this MOS-FET from burn-out due to excessive RF or static potentials, two back-biased shunt diodes are used connected back-to-back across the RF input. This is shown in the schematic diagrams of Figs. 7 and 8, for the low-frequency and high-frequency amplifiers, respectively.

In the low-frequency amplifier ( 150 to $250 \mathrm{kHz}$ ) the untuned input stage is followed by a 7 -pole Butterworth band-pass filter, the circuit of which is given in Fig. 9. This is in turn followed by a 3-stage, broadband, resistance-coupled amplifier using overall negative RF feedback to improve gain stability with respect to temperature and supply voltage variations. In the high-frequency amplifier ( 18 to $30 \mathrm{MHz}$ ) a 6-pole Tschebyscheff band-pass filter is used to determine the overall selectivity. The circuit diagram of this filter is shown in Fig. 10. The main amplifier has three stages using wide-band synchronously-tuned interstage transformers, with a low-Q LC tank in the collector circuit of the 


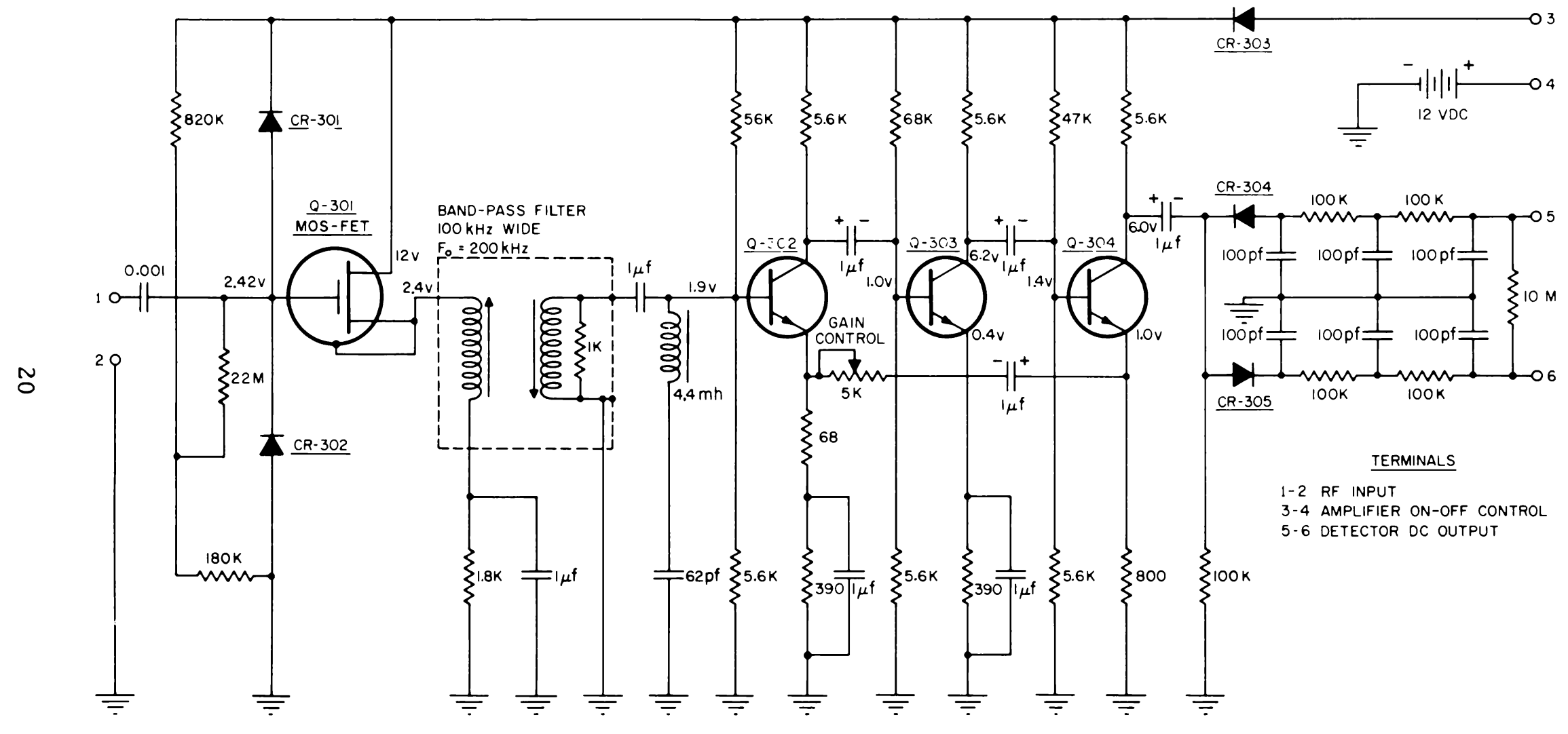

FIG. 7 CIRCUIT OF THE BAND-PASS RF AMPLIFIER ( 150 TO $250 \mathrm{kHz}$ ) 


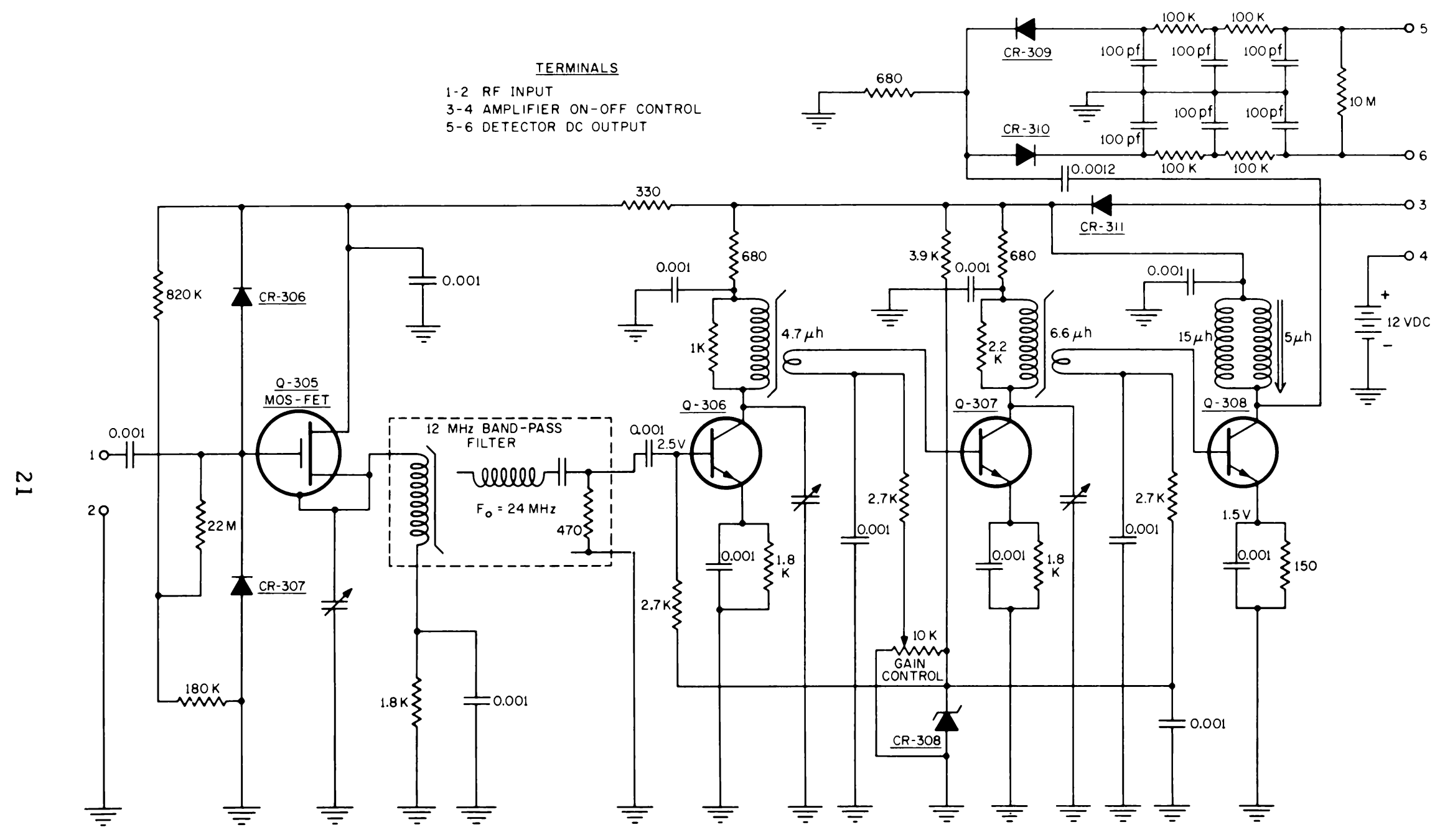

FIG. 8 CIRCUIT OF THE BAND-PASS RF AMPLIFIER ( 18 TO $30 \mathrm{MHz}$ ) 


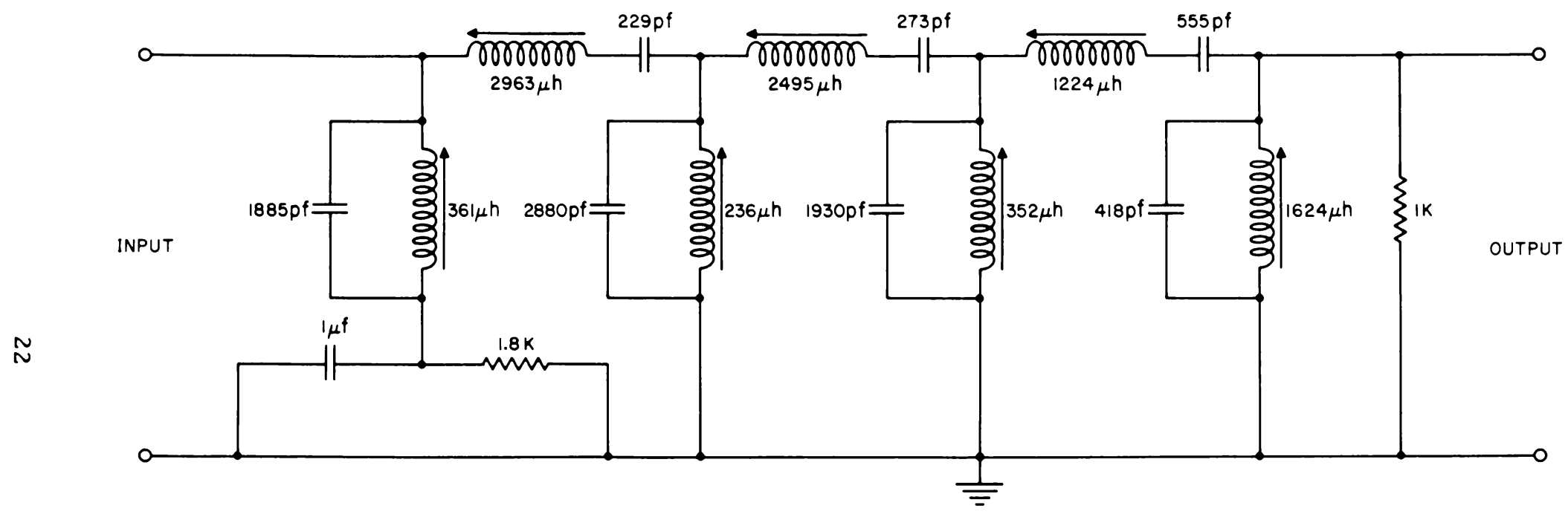

FIG. 9 SEVEN-POLE BUTTERWORTH BAND-PASS FILTER $\left(F_{0}=200 \mathrm{kHz}\right)$ 


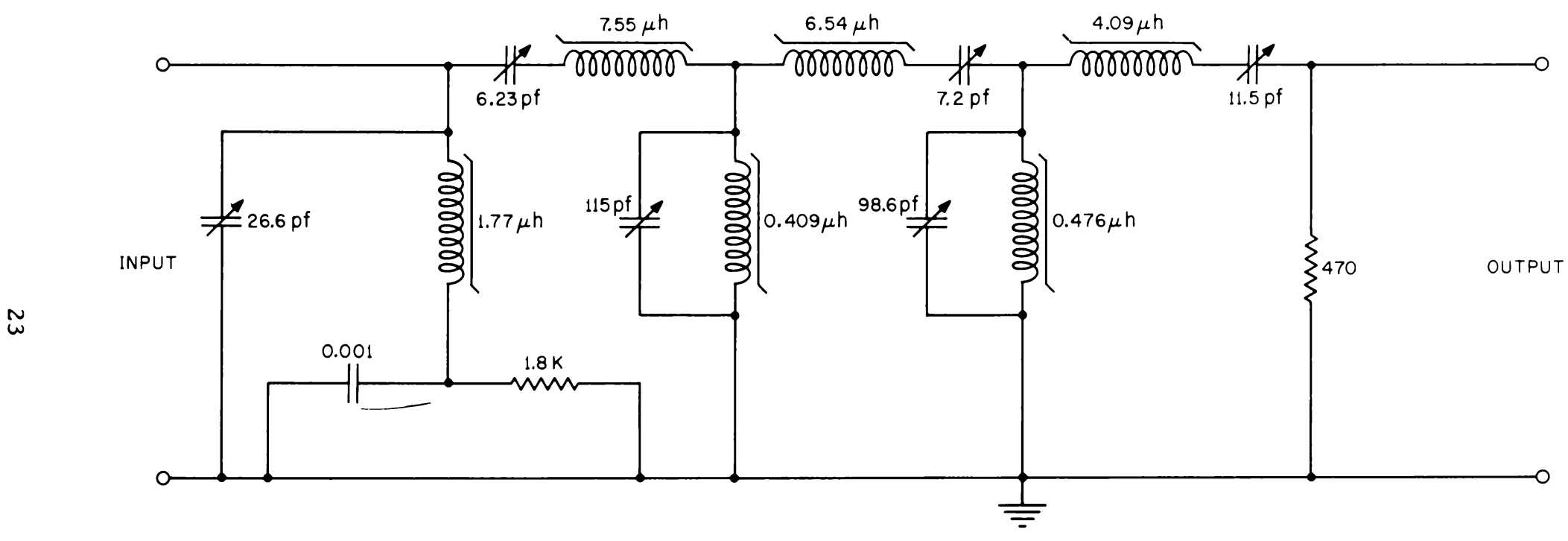

FIG. 10 SIX-POLE TSCHEBYSCHEFF BAND-PASS FILTER $\left(F_{0}=24 \mathrm{MHz}\right)$ 

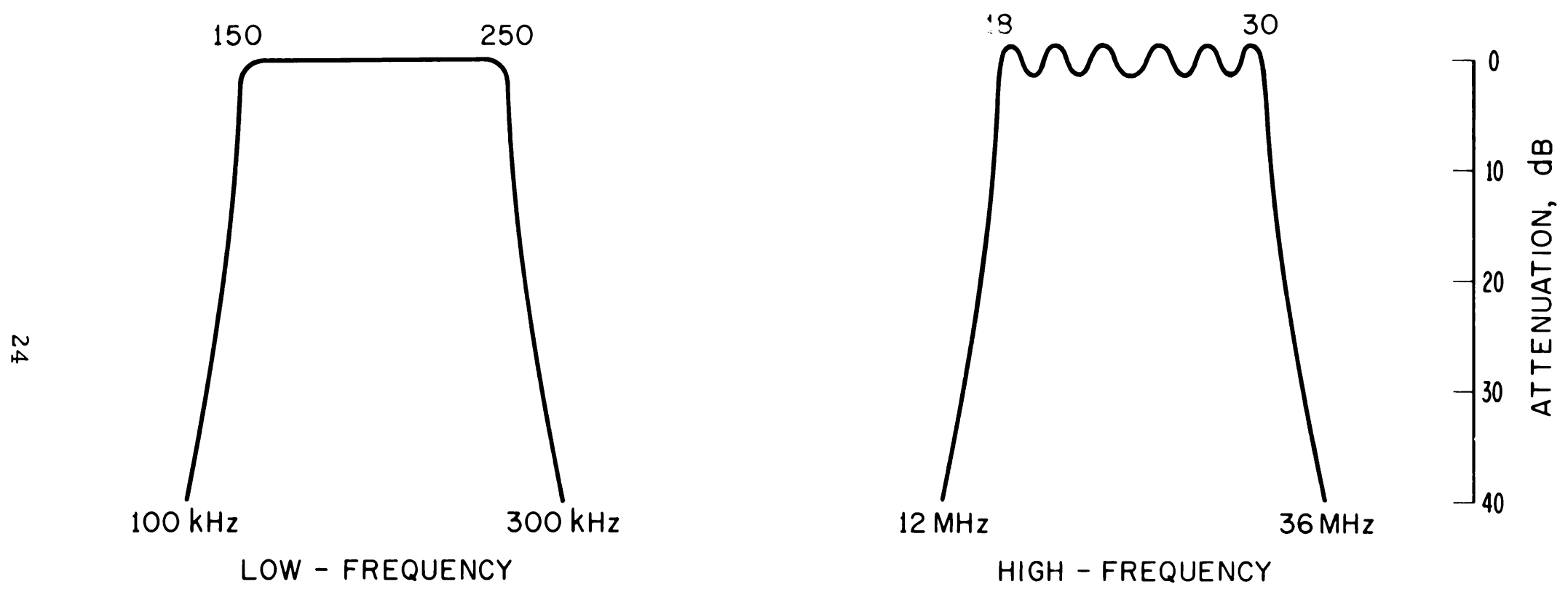

FIG. II NOMINAL OVERALL SELECTIVITY CHARACTERISTICS OF THE TWO BAND-PASS AMPLIFIERS 
final stage. These low $-Q$ tuned circuits do not contribute appreciably to the overall selectivity of the high-frequency amplifier, but do contribute to its stability and serve to reduce the output noise to a satisfactory level by limiting the bandwidth of this portion of the receiver. No overall negative RF feedback is employed in the design of this amplifier because of the difficulty in maintaining proper RF phase relations over the passband. However, the gain stability was improved by Zener-regulating the DC bias supplied to the bases of the three transistors.

The overall gain of both amplifiers can be manually adjusted to the required operating value, which is approximately $40 \mathrm{~dB}$. The output detectors of both amplifiers employ two stable silicon diodes in a voltage doubling circuit as shown. This eases somewhat the voltage-swing requirements on the final amplifier stage, and also reduces the battery drain accordingly. Subminiature rigid coaxial lines $1 / 16$ inch O. D. are used for the RF input and detector DC output leads, as indicated in Fig. 2. The nominal overall selectivity characteristics of the low-frequency and high-frequency band-pass amplifiers are shown in Fig. 11. The battery supply for the amplifiers is 12 volts, being composed of silveroxide cells in two paralleled stacks of eight cells each. A silicon diode is used, as shown, to provide reversed-polarity protection for the amplifier. This supply has a useful life of from 10 to 20 hours. The two bandpass amplifier modules were developed to NBS specifications by a private manufacturer and are approximately 1-1/4 inches $O$. D. by 5 inches long, overall, including the battery supply.

\subsubsection{Calibrating Oscillator and Detector.}

The basic circuit arrangement of the calibrating oscillators is shown in the block diagram of Fig. 12. The tuning range of each of the two oscillators is the same as the $3 \mathrm{~dB}$ bandwidth of the band-pass amplifier with which it is used, i. e., 150 to $250 \mathrm{kHz}$ for the low-frequency 


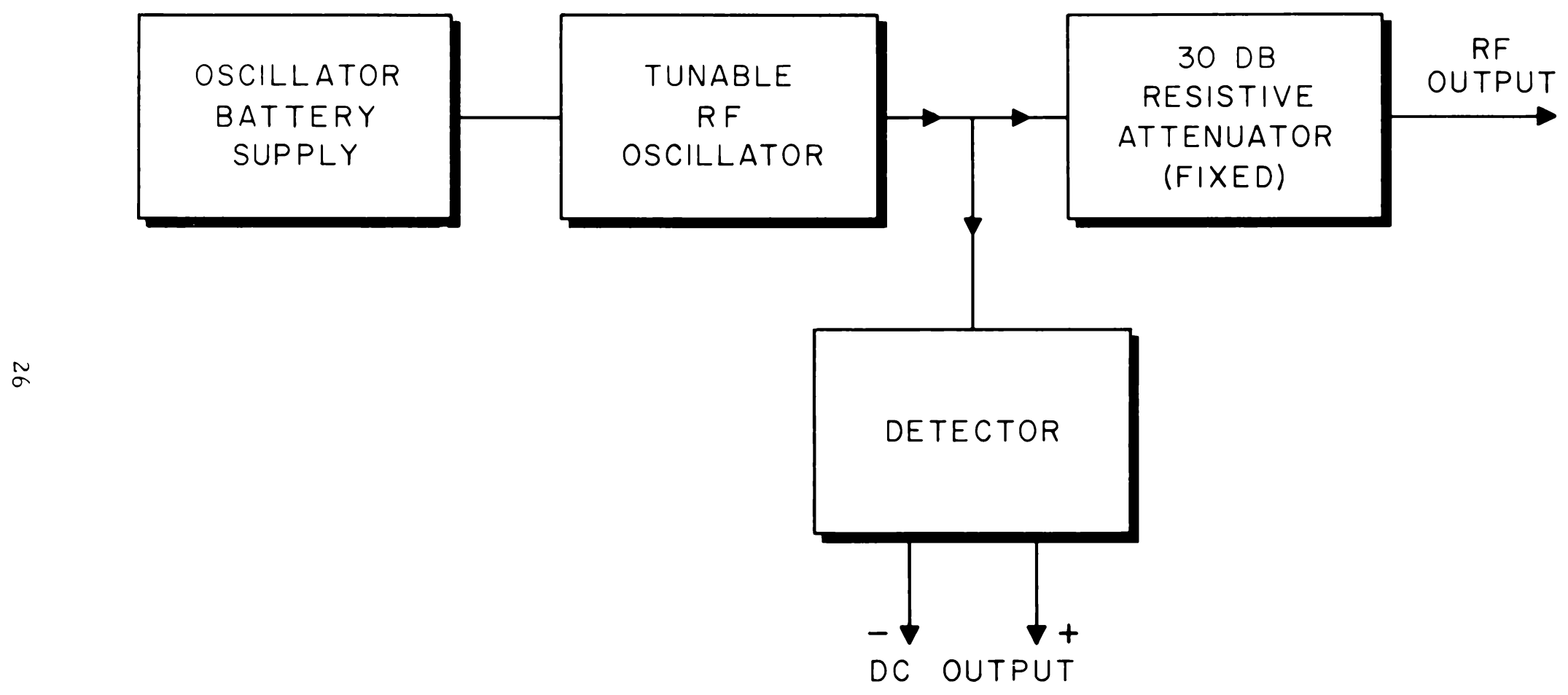

FIG. 12 BASIC LAYOUT OF CALIBRATING OSCILLATOR 
unit, and 18 to $30 \mathrm{MHz}$ for the high-frequency unit. The detailed circuitry of these two oscillators is shown in Figs. 13 and 14, respectively. Tuning is accomplished by means of a ferrite slug core, driven by a steel lead screw, as can be seen in Fig. 2. The inductor of the low-frequency unit is a four-layer progressive-universal winding having 500 turns of $7 / 44$ Litz wire, while that of the high-frequency oscillator is a singlelayer solenoid having 22 turns of No. 20 A. W. G. solid-copper wire. The windings are molded on the inside of an epoxy for $\mathrm{m}$ to minimize the air gap, and to increase the tuning range and $Q$. Tuning linearity is achieved by varying the winding pitch along the winding. An amplifier and AGC system is incorporated to maintain the oscillator RF output level essentially constant over the tuning range.

The RF output of the oscillator is adjustable to 3.16 volts and fed into the input terminals of a fixed 30-dB resistive attenuator pad. When calibrating the gain of the band-pass amplifier, the output of 0.1 volt from the pad is applied through a small variable capacitor (adjusted to approximately $3 \mathrm{pF}$ ) which simulates the dipole probe capacitance. The detector circuit is identical to that used with the band-pass amplifiers and employs two stable silic on diodes in a voltage-doubling circuit. The detector monitors the 3.16 volt RF oscillator level at the input terminals of the $30 \mathrm{~dB}$ pad. Subminiature rigid coaxial lines 1/16 inch O. D. are used for the RF output and detector DC output leads. The battery supply is essentially the same as that used with the band-pass amplifier unit, and uses two paralleled stacks of silver-oxide-cells (nine cells per stack). This gives a nominal supply voltage of 13.5 volts for the collector supply of the three transistors, as shown. A portion of this supply is Zenerregulated and applied to the transistor base circuits for improved amplitude stability over the useful life of the batteries, which is about 20 hours. The two calibrating-oscillator modules were developed to NBS specifications 


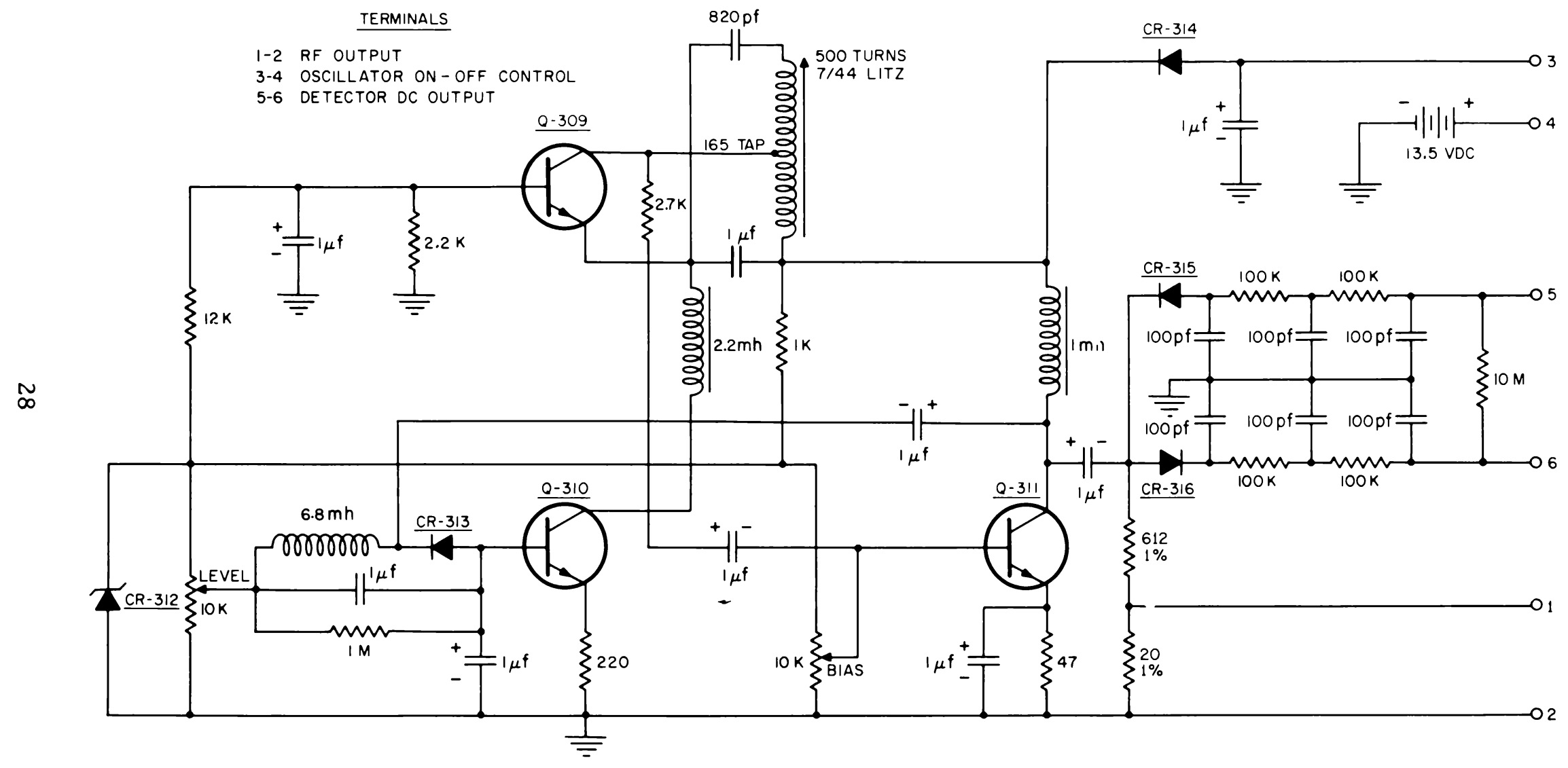

FIG. I3 CIRCUIT OF THE LOW-FREQUENCY CALIBRATING OSCILLATOR ( 150 TO $250 \mathrm{kHz}$ ) 


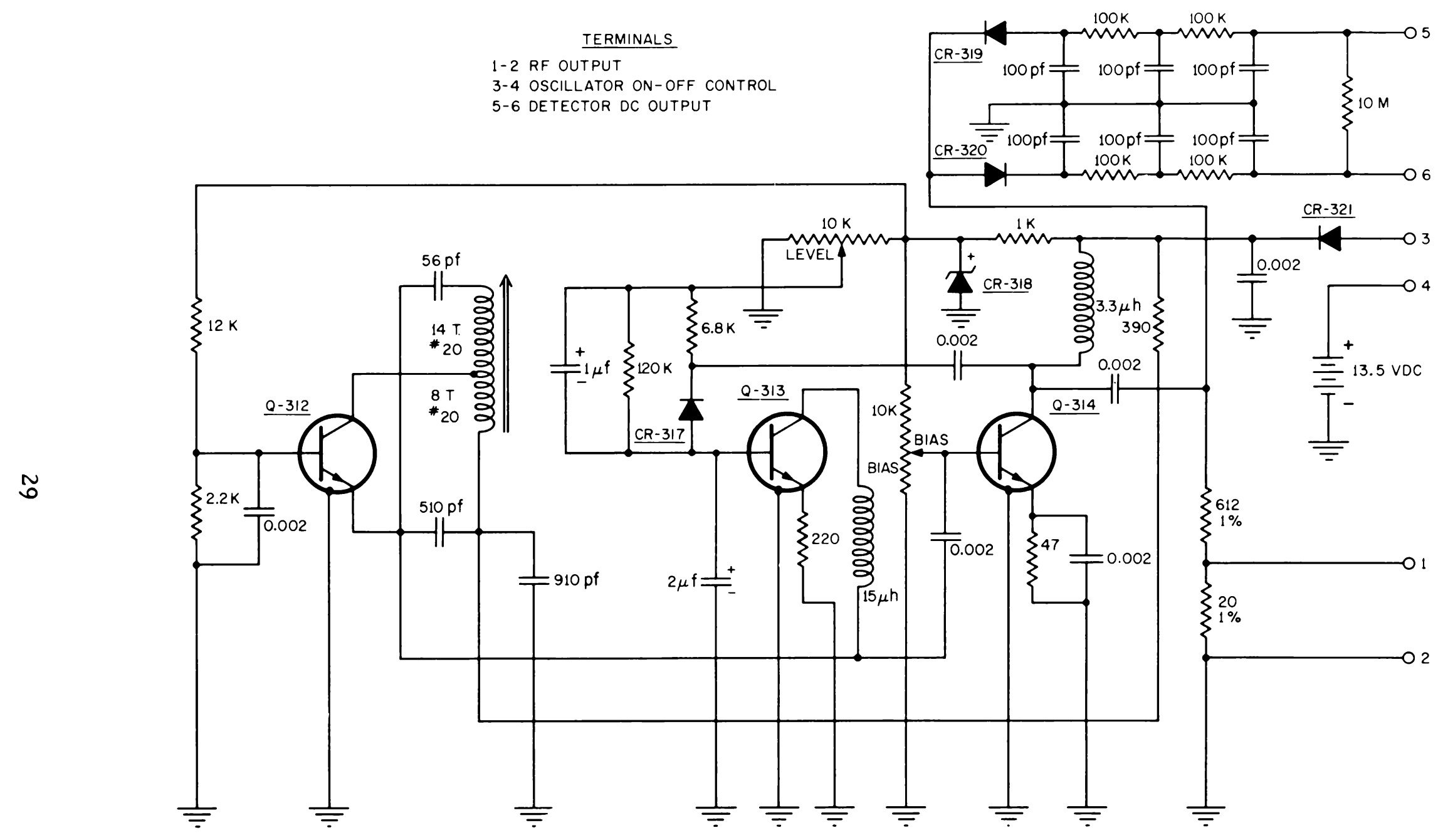

FIG. 14 CIRCUIT OF THE HIGH-FREQUENCY CALIBRATING OSCILLATOR ( 18 TO $30 \mathrm{MHz}$ ) 


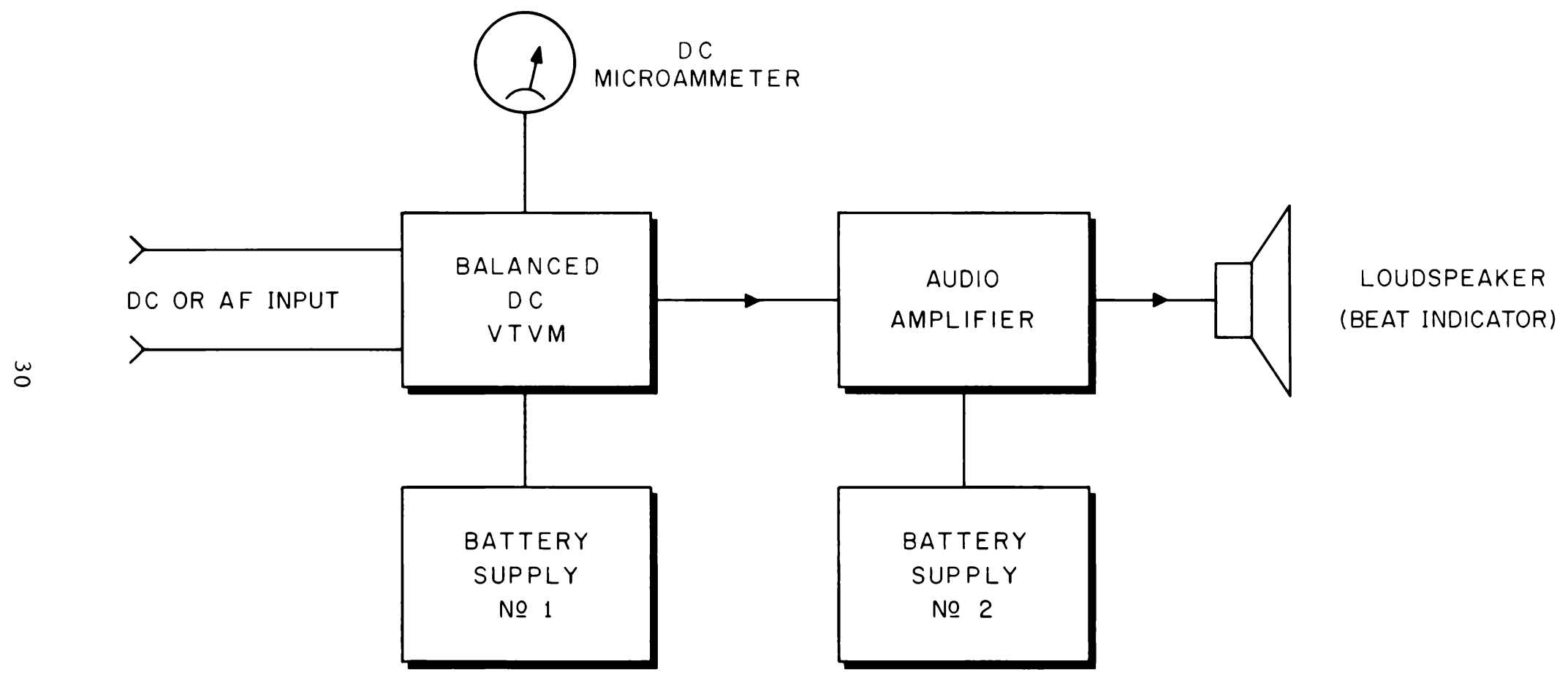

FIG. I5 BASIC LAYOUT OF REMOTE INDICATOR UNIT 
by a private manufacturer and are approximately $1-1 / 4$ inches $O$. D. by 5 inches long, overall, including the battery supply.

\section{2. 6 Remote Indicator Unit.}

The basic makeup of this unit is shown in the block diagram of Fig. 15. It consists, in the main, of a balanced DC vacuum-tube voltmeter with its DC microammeter, on which the magnitude of the electric field strength is indicated. The VTVM is a battery-operated unit and has extremely good stability and linearity of response because of the large amount of negative DC feedback used in its design. It is used over a single $20 \mathrm{~dB}$ input range of approximately 0.75 to 7.5 volts DC. A schematic circuit diagram of the VTVM is shown in Fig. 16.

The input circuitry of the VTVM is balanced to ground and provides from 40 to $60 \mathrm{~dB}$ rejection of common-mode input in the 60 to $400 \mathrm{~Hz}$ power-frequency range. In addition, a two-section balanced RF filter is used to suppress common as well as transverse-mode input at RF frequencies. This filter provides at least $40 \mathrm{~dB}$ suppression over the range from 2 to $30 \mathrm{MHz}$. The input resistance of the VTVM has been adjusted to approximately 200 megohms, making the DC voltage drop on the semiconducting transmission line less than 1.0 percent.

An output circuit of the VTVM is used to drive a transistorized audio amplifier and loud speaker contained in the same case with the VTVM, as indicated in the block diagram. This unit is of conventional design and is used as a zero-beat indicator when adjusting the frequency of the calibrating oscillator to that of the field being measured. It is always necessary to calibrate the gain of the RF amplifier in the fieldstrength meter at the particular frequency at which a measurement is to be made. The schematic circuit diagram of the AF amplifier is shown in Fig. 17 . 


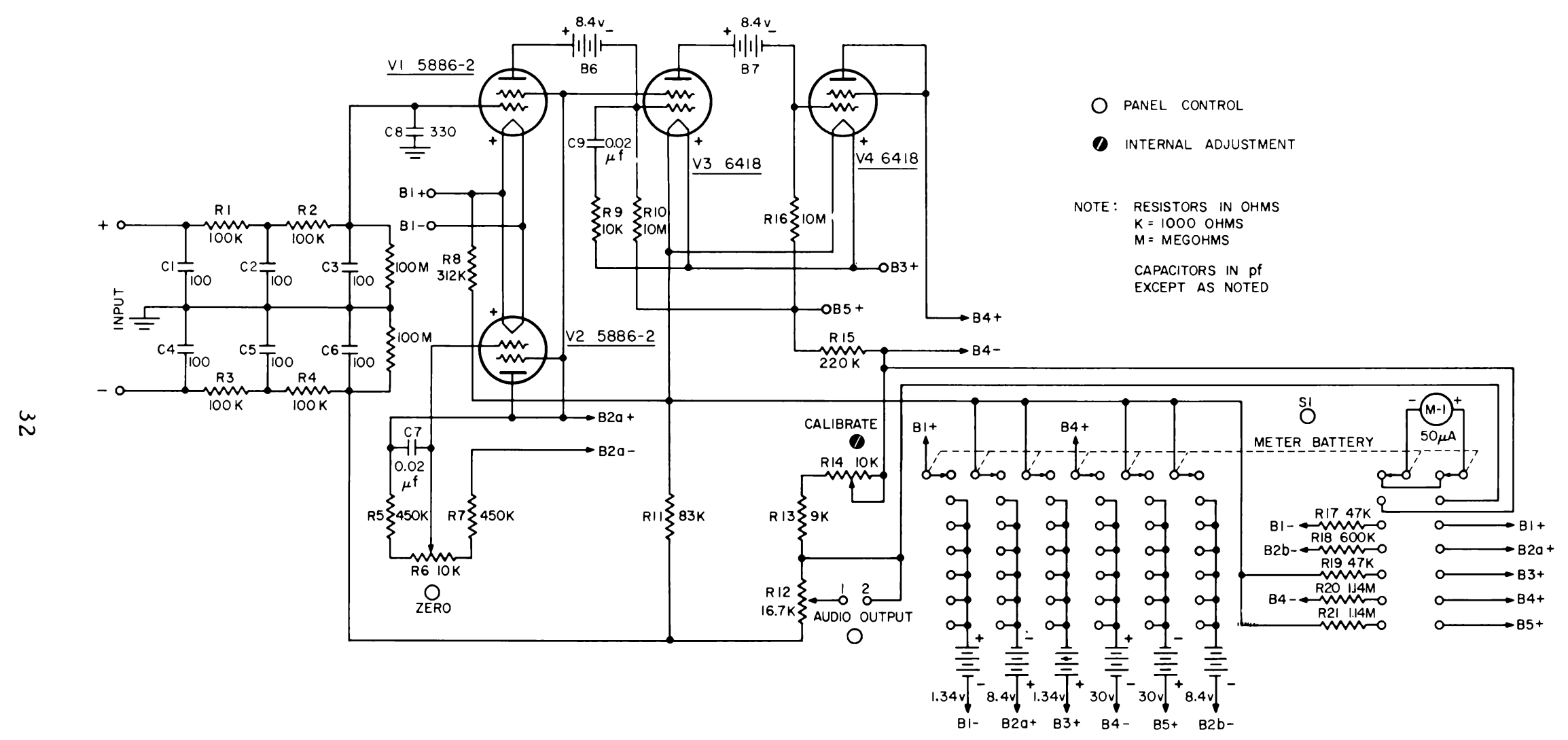

FIG. I6 CIRCUIT OF THE DC VACUUM-TUBE VOLTMETER 


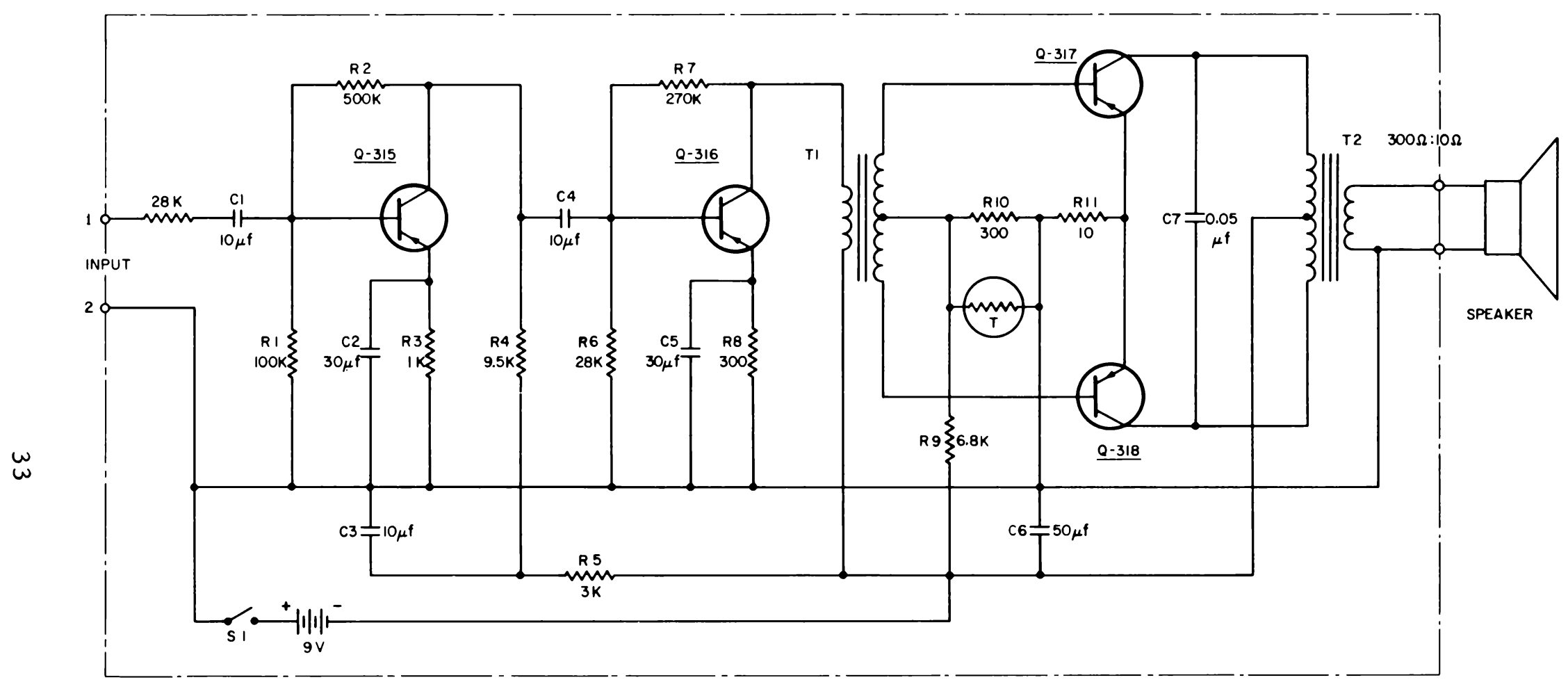

FIG. 17 CIRCUIT OF THE AUDIO-AMPLIFIER BEAT INDICATOR 


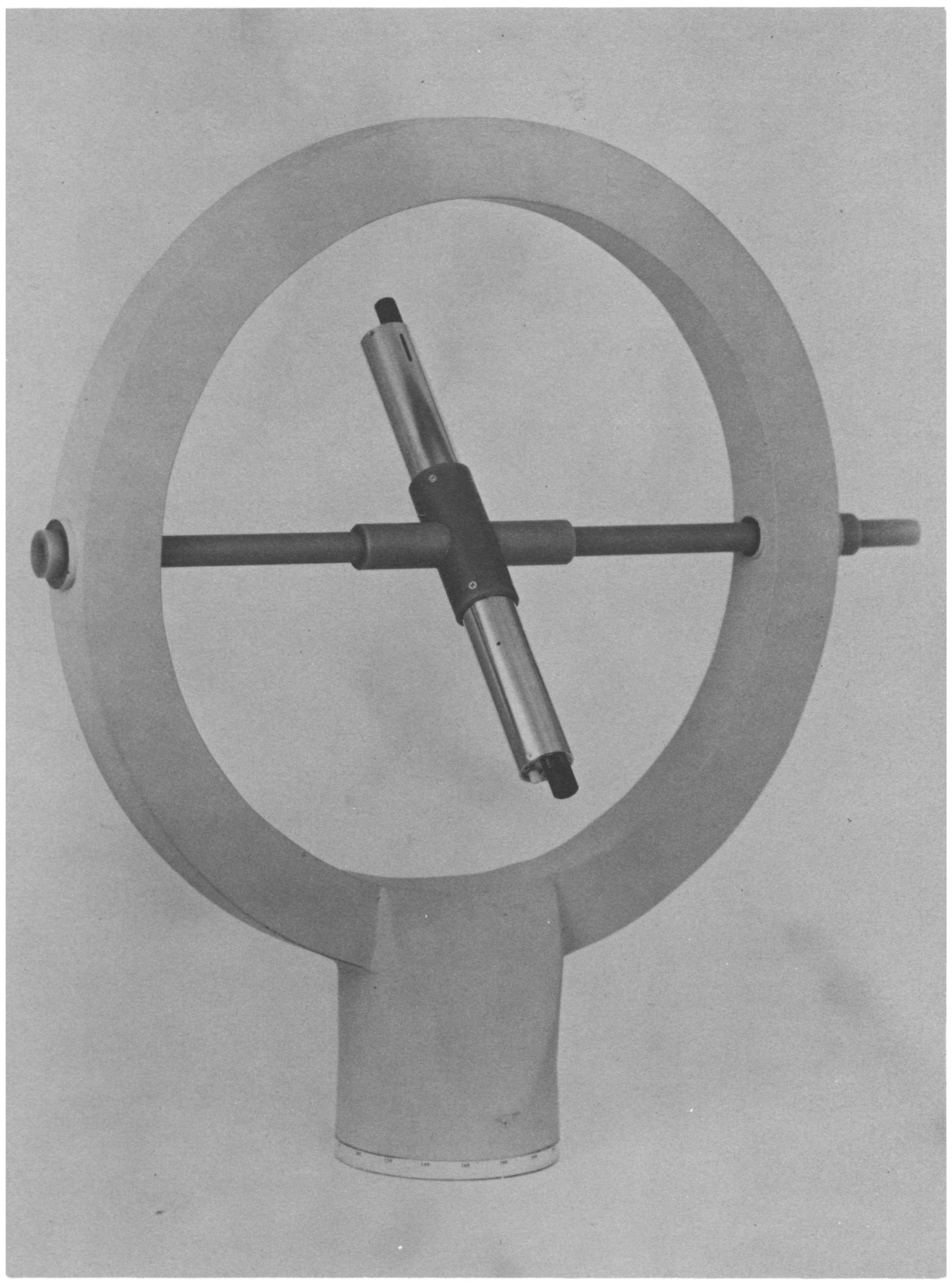

FIG. 18 VIEW OF THE MEASURING DIPOLE AND MOUNTING GIMBAL 
The DC-VTVM and AF amplifier each has its own self-contained battery supply. The complete remote indicator unit is housed in a drawnaluminum case, using a tight-fitting panel to minimize RF leakage into the unit. A small drawn-aluminum case is used to enclose the rear side of the DC microammeter to reduce RF entry through the meter face.

\section{2.7 The Assembled Field-Strength Meter.}

The measuring dipole of the near-zone TRF field-strength meter is mounted on a hollow fiberglass shaft which is perpendicular to the dipole axis. This shaft is, in turn, supported in plastic bearings in a circular reinforced polyfoam gimbal, approximately 21 inches in diameter, as shown in Fig. 18. The gimbal has been coated with a thin film of epoxy to increase its strength. This assembly is mounted on a sturdy wooden surveyor's tripod in such a manner that manual adjustments in azimuth and elevation can be readily made in the orientation of the dipole.

The complete field-strength meter consists of three units:

(a) the tripod-mounted dipole measuring antenna;

(b) the 30-foot "semi-conducting" plastic transmission line;

(c) the battery-operated remote-indicator unit.

A view of the complete operating instrument is shown in Fig. 19, in which these components can be seen. The balanced transmission line connects to the dipole through the hollow shaft on its right. A simple split cylindrical tool is used to facilitate inserting the twin-conductor transmission-line plug through this shaft. The other end of the line connects to the balanced input of the remote-indicator unit on the right. It is necessary to observe the correct polarity, as marked, when making this connection. A close-up view of this unit is shown in Fig. 20. 


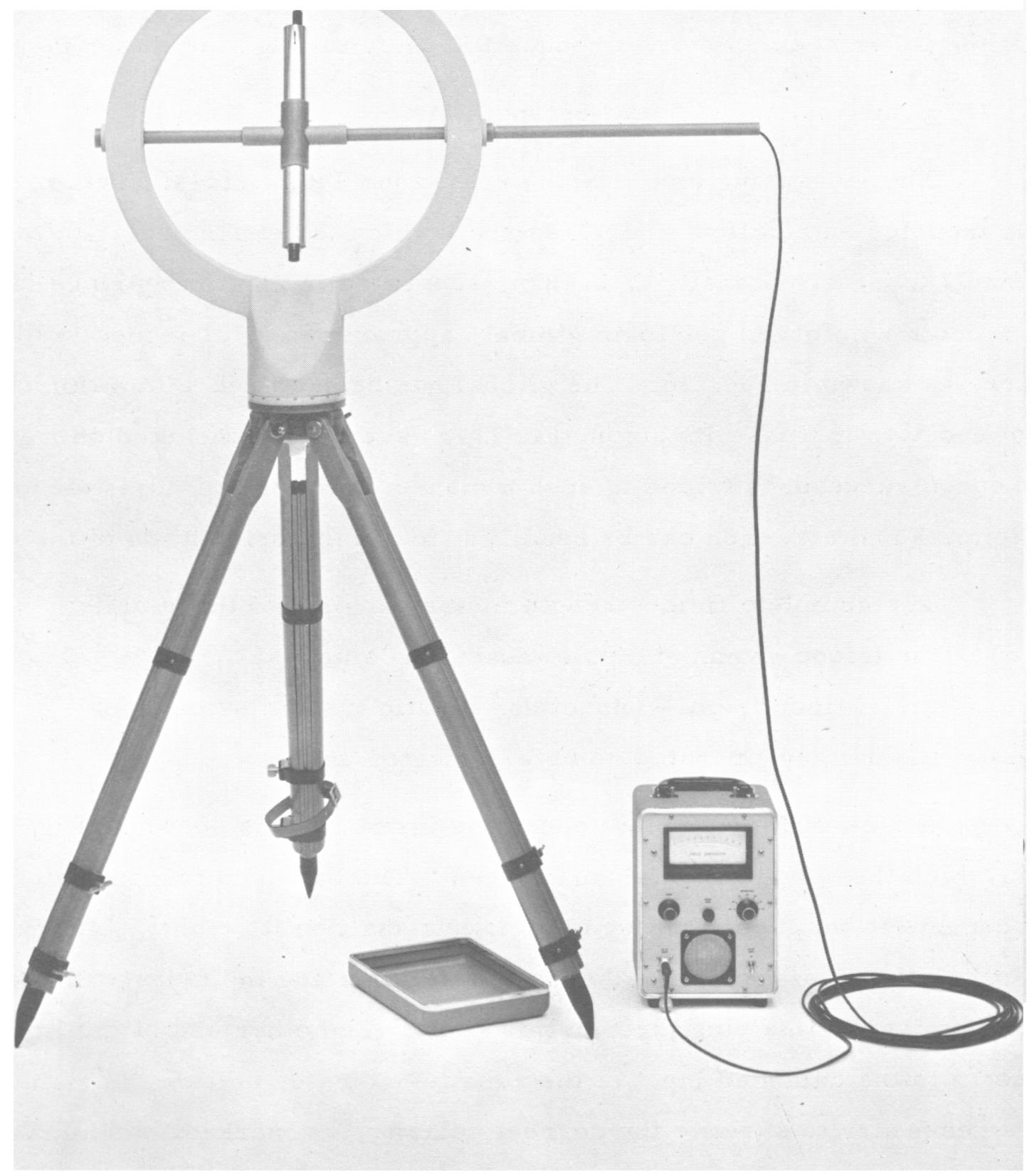

FIG. I9 THE COMPLETE NEAR-ZONE FIELD-STRENGTH METER 


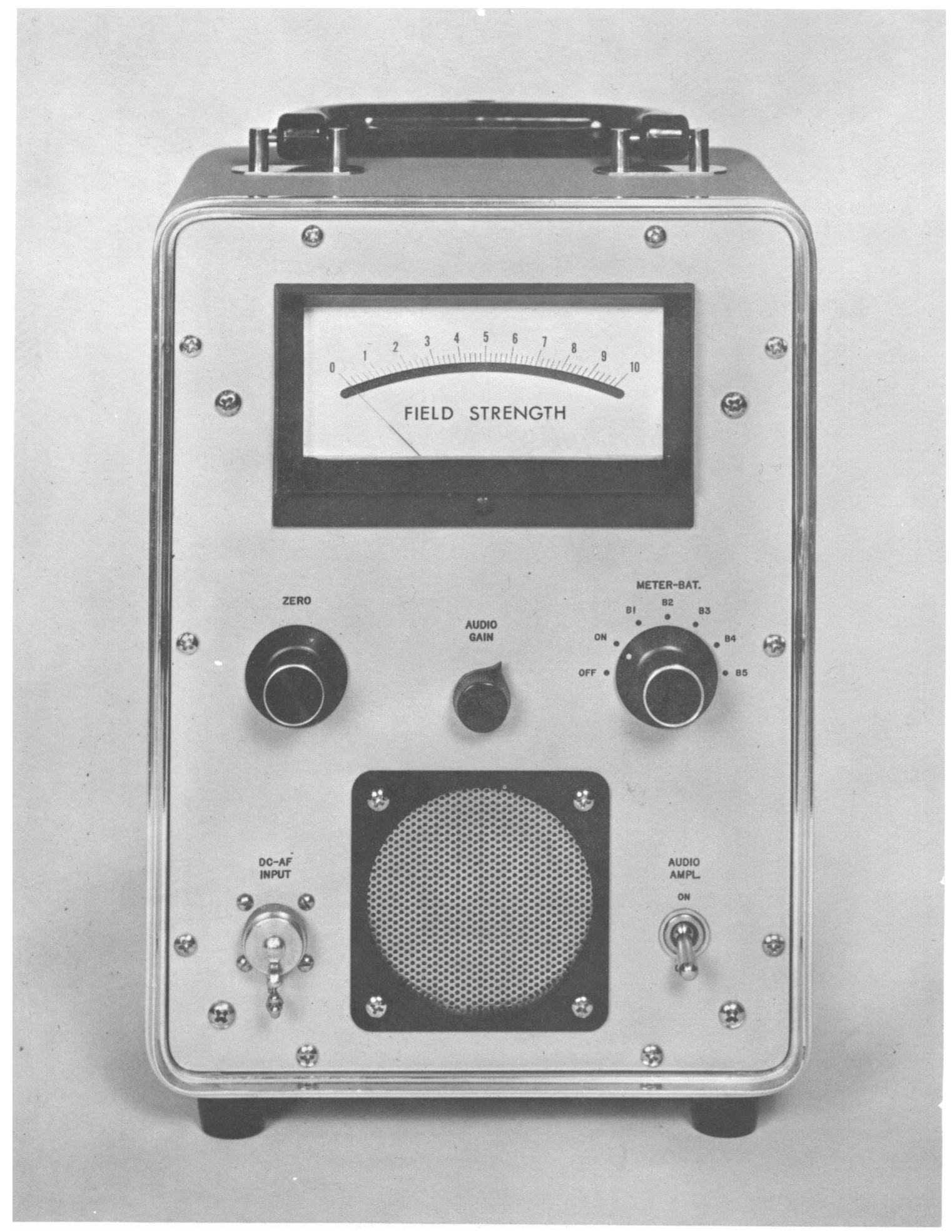

FIG. 20 VIEW OF THE REMOTE INDICATOR UNIT 
- NOTES - 


\section{DASA Final Acceptance Tests}

\section{1 General.}

The completed NBS near-zone TRF field-strength meters underwent extensive acceptance tests at the U. S. Naval Weapons Laboratory at Dahlgren, Virginia, during the week from October 18 to October 22, 1965. The tests were conducted by FCDASA and NBS-BL personnel and were witnessed by several representatives of each of the three branches of the Department of Defense. Of great assistance in the tests were the NWL metal ground plane No. 2 ( 100 by 240 feet in size), made of welded sections of $3 / 8$ inch steel plate, and the Navy transmitting equipment with sufficient power to produce the required test field strengths at the specified frequencies.

\section{2 Low-Frequency Tests.}

The low-frequency TRF field-strength meter was tested at a frequency of $185 \mathrm{kHz}$, using vertically-polarized electric fields with strengths up to 1020 volts per meter. The test fields were established between a large horizontal "fan" antenna and the metal ground plane. The "fan" was in the approximate shape of an equilateral triangle, about 100 feet long on a side and supported by three wooden poles. The "fan" was composed of 14 diverging wires, connected at their common end to a single-wire feed line, and supported by one of the poles. At their opposite end, the fanned wires connected to a messenger cable stretched between the other two poles. The height of the horizontal fan was adjusted to approximately 14 feet above the ground plane at the lowest point (Station 3), increasing to 18 feet at the three points of support.

A Navy Type AN/FRT-39 transmitter having a CW RF power output of approximately 2 kilowatts was used to excite the antenna system. The transmitter was housed in one of the vans located beside the ground plane. 


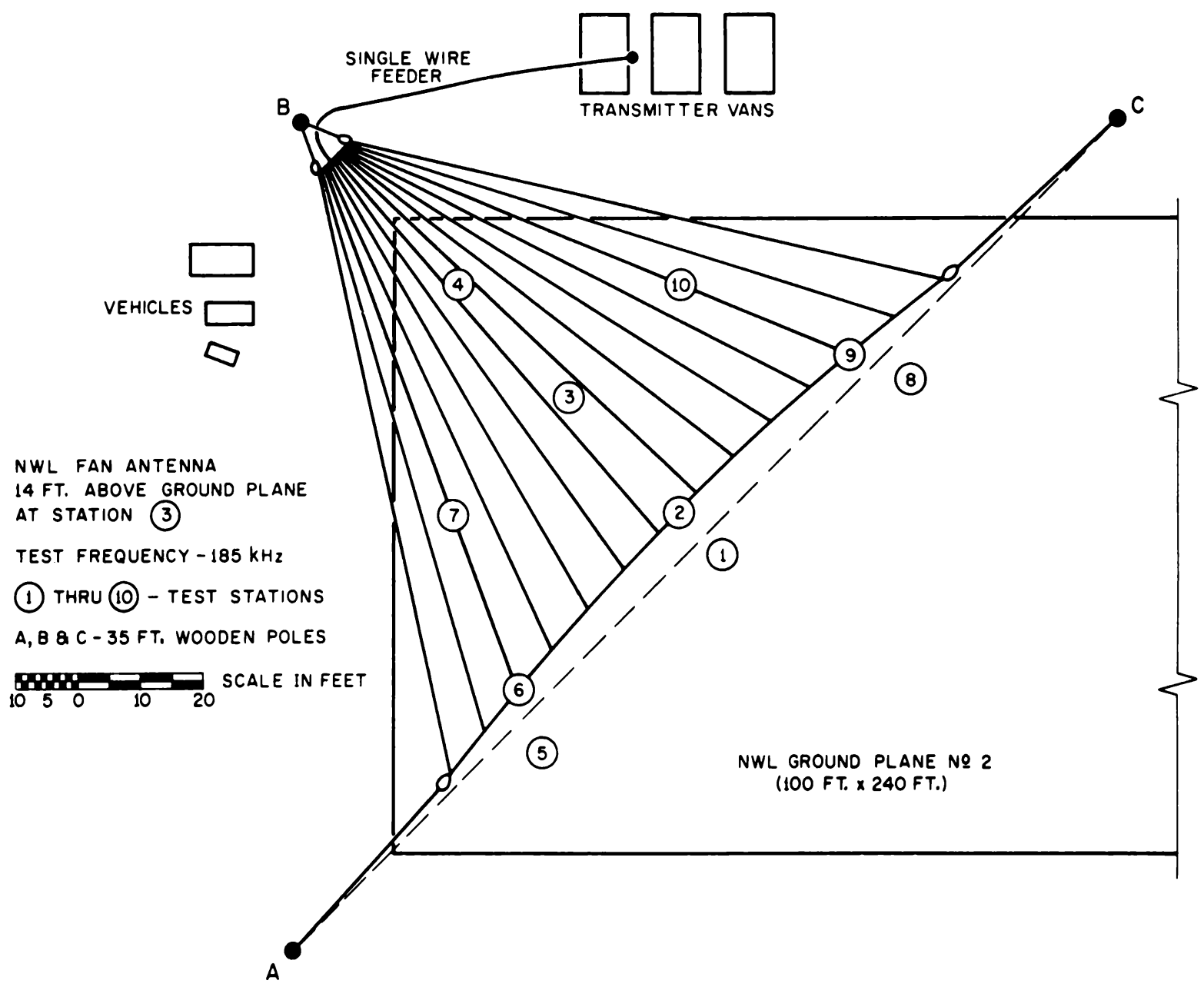

NWL FAN ANTENNA

$14 \mathrm{FT}$. ABOVE GROUND PLANE AT STATION (3)

TEST FREQUENCY $-185 \mathrm{kHz}$

(1) THRU (10) - TEST STATIONS

$A, B$ \& C - 35 FT. WOODEN POLES

$1050 \quad 10 \quad 20$

FIELD - STRENGTH MEASUREMENTS

\begin{tabular}{|l|c|c|c|c|c|c|c|c|c|c|c|c|c|c|c|}
\hline STATION NUMBER & (3) & $(1)$ & $(2)$ & $(2)$ & $(3)$ & $(4)$ & $(5)$ & $(6)$ & $(6)$ & $(3)$ & $(7)$ & $(8)$ & (9) & (10) & (3) \\
\hline ANTENNA CURRENT $\left(I_{A}\right)$ & 13.0 & 12.9 & 12.4 & 13.0 & 13.0 & 12.8 & 13.0 & 12.6 & 13.0 & 13.0 & 12.7 & 12.9 & 13.0 & 13.0 & 13.0 \\
\hline FIELD STRENGTH $(\mathrm{V} / \mathrm{m}) *$ & 1020 & 240 & 440 & 460 & 1020 & 880 & 210 & 420 & 440 & 1020 & 920 & 220 & 460 & 980 & 1020 \\
\hline
\end{tabular}

\begin{tabular}{|l|l|c|c|c|}
\hline UNBALANCE TEST & DIPOLE ORIENTATION & $0^{\circ}$ & $180^{\circ}$ & $0^{\circ}$ \\
\cline { 2 - 5 } AT STATION (3) & INDICATED V/m & 1020 & 1020 & 1020 \\
\hline
\end{tabular}

\begin{tabular}{|c|c|c|c|c|c|c|}
\hline \multicolumn{2}{|c|}{ COMMON MODE TEST AT STA. (3) } & \multicolumn{3}{|c|}{$\begin{array}{l}\text { REMOTE INDICATOR AND LINE MOVED AND } \\
\text { HANDLED IN STRONG FIELD }\end{array}$} & \multicolumn{2}{|c|}{$\begin{array}{l}\text { NO CHANGE IN } \\
\text { INDICATED } \mathrm{V} / \mathrm{m}\end{array}$} \\
\hline \multirow[t]{2}{*}{ RF - SHIELDING } & \multirow[t]{2}{*}{ TEST AT STA. (3) } & TEST CONDITIONS & $\begin{array}{l}\text { AMPL. "ON" } \\
\text { (6O db STEP) }\end{array}$ & $\begin{array}{l}\text { AMPL. "ON", } \\
\text { DIPOLE } \\
\text { SHORTED } \\
\text { (O db STEP) }\end{array}$ & $\begin{array}{l}\text { AMPL."OFF," } \\
\text { DIPOLE } \\
\text { SHORTED } \\
\text { (Odb STEP) }\end{array}$ & $\begin{array}{l}\text { REMOTE } \\
\text { INDICATOR } \\
\text { UNIT ONLY }\end{array}$ \\
\hline & & INDICATED $\mathrm{V} / \mathrm{m}$ & 1020 & 1 & 0 & 0 \\
\hline
\end{tabular}

FIG. 21 LOW-FREQUENCY DASA ACCEPTANCE TESTS 
The total antenna RF current was measured in the single-wire feed line at the transmitter and included any stray current that existed to ground. The antenna layout, the locations of the test stations, as well as the test results are shown in Fig. 21. All measurements were made with the center of the dipole antenna of the field-strength meter at a vertical height of 4.3 feet above the ground plane. Values of electric-field strength were measured over the range from 210 to 1020 volts per meter with good reproducibility. Both the dipole unbalance and the commonmode pickup were found to be negligible (less than 1 percent), as indicated. RF shielding of the dipole was effective to approximately $60 \mathrm{~dB}$, as measured in a 1020 volt-per-meter field. Susceptibility tests were also performed which are not indicated in Fig. 21. No measurable susceptibility was found to an interfering $22.91 \mathrm{MHz}$ signal (on alone, or simultaneously), having a strength of 200 volts per meter. The remoteindicator unit was placed in the direct beam of a Type AN/SPS-17 P-Band (222 $\mathrm{MHz}$ ) radar, about 70 feet from its antenna which was radiating a peak power of about 750 kilowatts. A copper wire several feet long was attached to the input connector of the remote-indicator unit which was held by the operator. The meter showed no indication whatsoever, and the unit was able to withstand the intense RF input without damage. Another scanning radar was in operation near the test site, but the lowfrequency TRF meter showed no measurable susceptibility when in its beam.

It was not considered feasible to attempt a theoretical evaluation of the electric-field strength existing between the "fan" antenna and the ground plane. This might have been achieved had it been possible to accurately evaluate the antenna capacitance. However, the uncertain boundary conditions existing prevented this. Unfortunately, as a result, there are no values of theoretical field strength with which to compare these test measurements. 


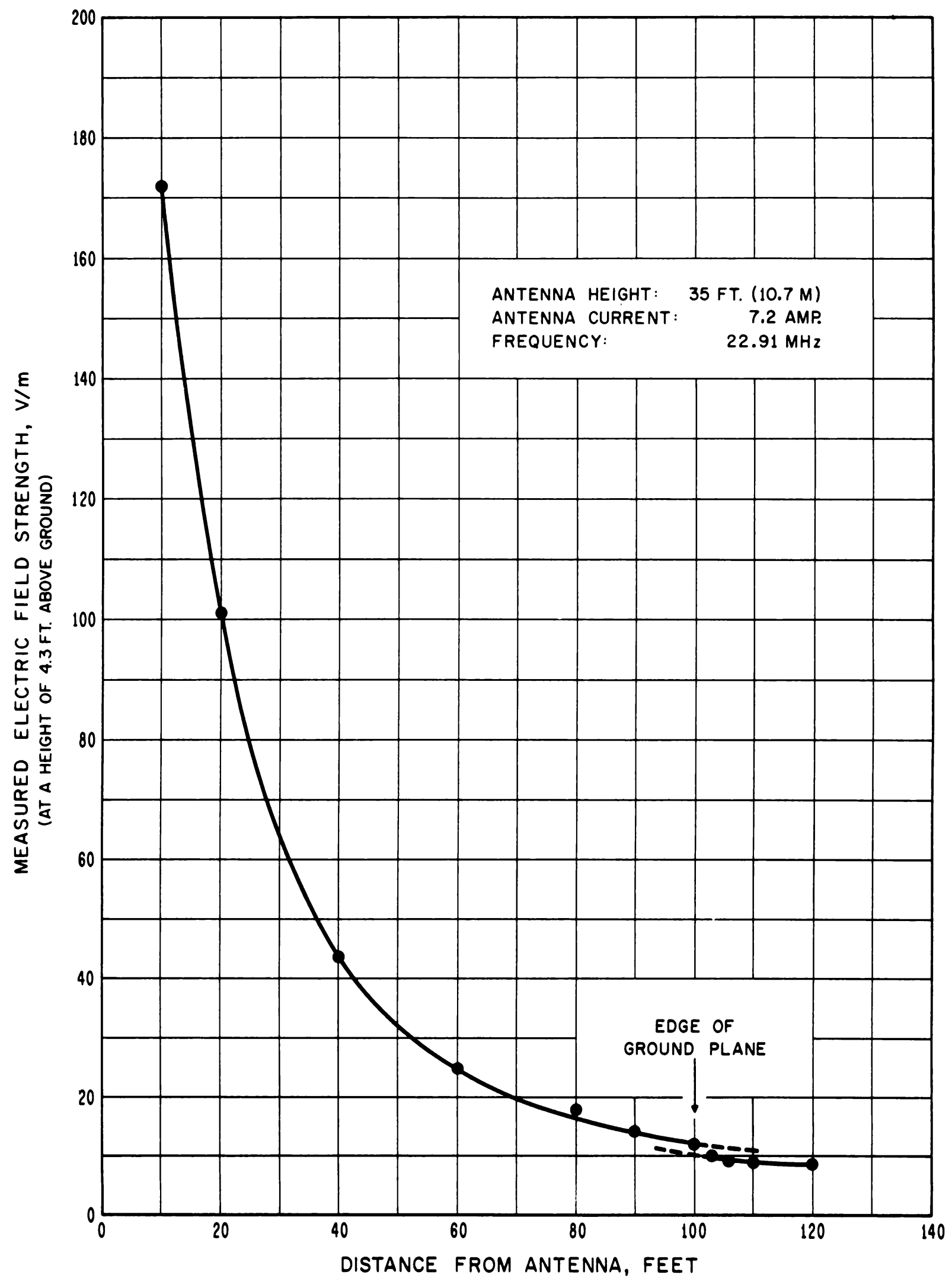

FIG. 22 VERTICAL ELECTRIC FIELD OF A 35 FT. MONOPOLE 
4. 3 High-Frequency Tests.

The high-frequency TRF field-strength meter was tested at a frequency of $22.91 \mathrm{MHz}$. This was one of the normally used transmitter frequencies nearest the center of the passband of the instrument. In the first group of tests, the electric field was produced by a 35-foot selfsupporting vertical monopole with a base current of 7.2 amperes. The antenna was located at the edge of the ground plane near the transmitter vans. It was excited by a Navy Type AN/FRT -5 transmitter having a nominal power output of approximately 15 kilowatts. No attempt was made to determine the theoretical field distribution of this antenna because of the uncertain boundary conditions involved.

Field-strength measurements were made at a height of 4.3 feet $(\lambda / 10)$ above the ground plane at eleven points extending horizontally in a line from the antenna across the ground plane to a point 20 feet beyond the opposite edge (over bare ground). The results of these measurements are shown plotted in Fig. 22, over the range from 8 to 172 volts per meter.

Similar tests to the above were performed using a self-resonant quarter-wave vertical monopole located at the center of the metal ground plane. The same test frequency (22.91 MHz) was used, with antenna base currents of 4.3 and 9.0 amperes. The antenna was a No. 14 A.W.G. copper wire, supported on plastic stand-off insulators mounted on a thin wooden mast ( 2 inches by 2 inches). A small loop was formed in the wire at the top to minimize corona discharge, and an RF thermocouple type ammeter was inserted at the base. The transmission feed line used was $50 \mathrm{ohm}$ Type RG-221/U low-loss coaxial cable, lying on the ground plane with the sheath grounded near the base of the antenna and the inner conductor connected directly to one of the ammeter terminals. The calculated 


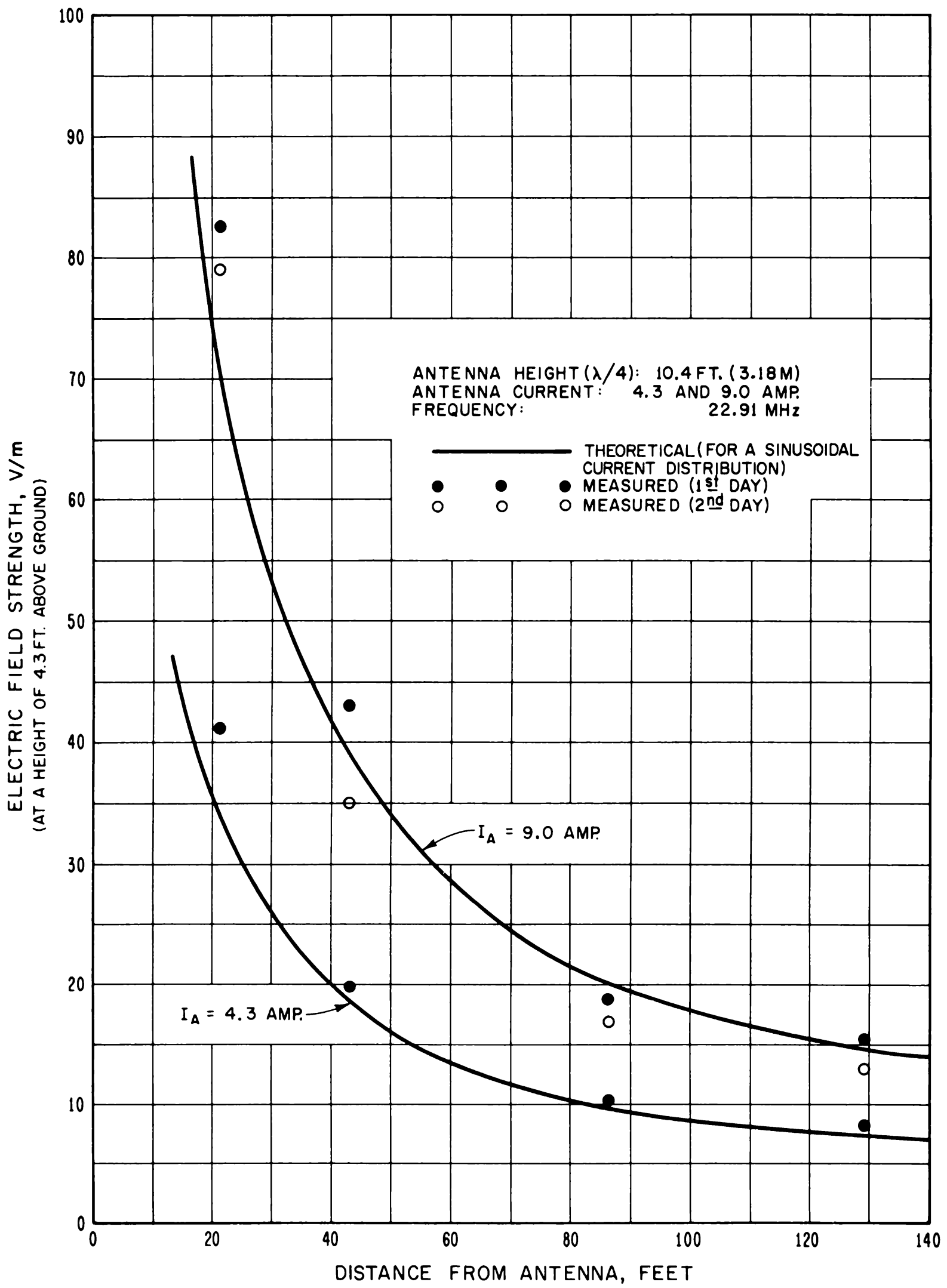

FIG. 23 VERTICAL ELECTRIC FIELD OF A $\lambda / 4$ MONOPOLE 
self-resonant antenna length was $10.4 \mathrm{feet}$, which included an estimated 3 percent shortening due to end effect.

Field-strength measurements were made on two successive days at a height of 4.3 feet above the ground plane, at horizontal distances of $0.5,1.0,2.0$, and 3.0 wavelengths from the antenna. The results are shown in Fig. 23 over the range from roughly 7 to 83 volts per meter. Also shown for comparison is the theoretical field for this antenna based on an assumed sinusoidal current distribution. The measurements agree in general with the theoretical values to within about one dB. The use of an assumed sinusoidal current distribution introduced some error in the computed values of field strength, but this is probably not large because of the small diameter of the antenna ( 0.064 inch). The effect of edge reflections from the ground plane is another factor that may have introduced additional uncertainty, although this is also believed to be small in this case. The dipole unbalance and common-mode pickup were found to be negligible (less than 1 percent). No penetration of the field into either the dipole or the remote-indicator unit could be observed in a 200 volt-per-meter field. No measurable susceptibility was found to an interfering $185 \mathrm{kHz}$ signal (on alone, or simultaneously), having a strength of 300 volts per meter. The unit showed no susceptibility to the scanning radar mentioned in Section 4.2 .

\section{4 Summary of the Tests.}

The NBS TRF meters showed the capability of measuring electricfield strengths without difficulty over the entire range from 0.1 to 1000 volts per meter (RMS). The tests demonstrated the simplicity of operation of the NBS TRF meters and the reproducibility of measurements free of the perturbing effects of metallic transmission lines usually experienced. There was no observable interaction between the semiconducting transmission line used and the field being measured. In 
general, the agreement was about $\pm 1 \mathrm{~dB}$ between the instrument readings as calibrated in the NBS (vertical monopole) standard field at Boulder and those obtained using a similar technique at NWL at Dahlgren. While this agreement may be somewhat fortuitous, it was also felt to be quite remarkable when considering all the various factors involved at the two sites.

\section{Acknowledgement}

The work described in this paper was performed for the Field Command, Defense Atomic Support Agency, under DASA Order HD-11023171-0001 (June 20, 1963).

The author wishes to acknowledge the valuable assistance of Mr. William E. Jessen of NBS-BL in the assembly and performance evaluation of the instrumentation described herein. The assistance of Mr. Ezra B. Larsen in the standard-field development work is also gratefully acknowledged. 


\section{Bibliography}

[1] Stoker, W. C., et al, An Investigation of Electromagnetic Coupling Devices for the Measurement of Noise Fields, Final Report, Rensselaer Polytechnic Institute, Troy, N. Y., Signal Corps Contract No. DA 36-039 sc-207, September 1952.

[2] Abromavage, M. M., et al, Electromagnetic Coupling to Ordnance Systems, Report No. N178-7604, August 1961, Jansky \& Bailey Div., Atlantic Research Corp., Alexandria, Virginia.

[3] Bartfeld, R. A. , et al, Study of Methods of Improved Measurement for Electromagnetic Field Components, Final Report, 26 May 1960 to 30 June 1962, University of Pennsylvania, Philadelphia, Pennsylvania, USNCEL Contract NBy-3200.

[4] Cowles, W. W. , et al. , Study of Methods of Implementing Poynting Vector Measurements, Final Report 1 July 1962 to 31 December 1964, University of Pennsylvania, Philadelphia, Pennsylvania, USNCEL Contract NBy-32219.

[5] Harrison, R. P., and Lewis, E. A., A Method for Accurately Measuring the Vertical Electric Field Strength of a Propagating VLF Wave, IEEE Trans. On I \& M, VIM-14, P1/2, pp. 89-97, March-June 1965.

[6] Clark, D. B., et al, Electromagnetic Field-Strength Measurements in a Quasi-Absolute Monopole Field, Final Report, August 1963 to October 1964, TR-R-361, U. S. Naval Civil Engineering Lab. , Port Hueneme, California, March 1965.

[7] Cowdell, R. B., HERO Ground-Plane Measurements and Development of the Near-Field Field-Intensity Meter, Final Report No. 2667-7 191, 30 April 1965, and Addendum No. 1, July 1965, Genistron, Incorporated, College Park, Maryland. 

S.9.

(2)

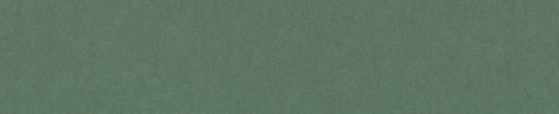

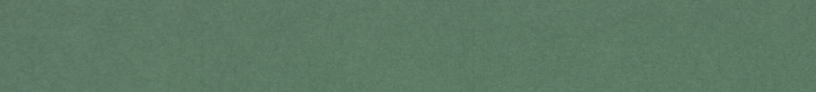

(3)

(2)

2.7.

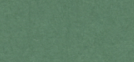

251 
U.S. DEPARTMENT OF COMMERCE

WASHINGTON, D.C. 20230

\section{OFFICIAL BUSINESS}

POSTAGE AND FEES PAID U.S. DEPARTMENT OF COMMERCE 